\title{
ÁLVARO DE CADAVAL, PRIMER LATINISTA DE LA UNIVERSIDAD DE SANTIAGO: UNAS NOTAS ${ }^{1}$
}

\author{
Por \\ MANUEL C. DÍAZ Y DÍAZ
}

Es de señalar que, como en otros casos conocidos, lo que quiere significar el título de estas notas es que Don Alvaro de Cadaval es el primer profesor de Letras latinas en la Universidad Compostelana de nombre conocido. Ignoramos mucho de su vida y obras; pero de los que fueron antes de él aún sabemos menos ${ }^{2}$. Me quiero entretener con su memoria y

\footnotetext{
1 Versión ampliada y dotada de anotaciones de la conferencia pronunciada el 12 de diciembre de 1995 en la Facultad de Filología de la Universidad de Santiago al conmemorarse el $25^{\circ}$ aniversario de la creación de la Sección de Filología Clásica.

${ }^{2}$ La bibliografía es escasa, por falta de estudios monográficos consistentes. Cuanto se puede aducir son resúmenes o repertorios de uso común, en los que menciono, con distinto valor documental, los siguientes, fundamentales a pesar de sus años: H. Flórez, España Sagrada, 23, Madrid 1767, 35-37; F. Avila y La Cueva, Historia Civil y Eclesiástica de la Ciudad de Tuy y su Obispado, I, 1852 (esta importante obra, nunca editada y muchas veces aprovechada, acaba de aparecer en Santiago 1995 en edición facsímil, que utilizo; la mención extensa de nuestro personaje y su familia en I, 255-262); Murguía, Diccionario de escritores gallegos, Vigo 1862, 132. Valioso también B. Varela Jácome, Historia de la Literatura Gallega, Santiago 1951, 71-72. Noticias diversas, con pequeños resúmenes de contenido de sus obras, en A. Couceiro Freijomil, Diccionario biobibliográfico de escritores, I, Santiago 1951, 190-193. Una cantidad de informaciones preciosas se pueden recoger en la breve pero densa página que le dedica L. de Matos, L'Expansion portugaise dans la Littérature latine de la Renaissance, Lisboa 1991, 512. Lo menciona sólo de pasada, como «poeta novilatino galego, residente em Portugal», el insigne investigador conimbrigense A. da Costa Ramalho, Estudos sobre a época do Renascimento, Coimbra 1969, 358 n. 4. Otras aportaciones serán presentadas a lo largo de estas páginas.
}

"CUADERNOS DE ESTUDIOS GALLEGOS", Tomo XLIII, Fascículo 108, Santiago 1996. 
remembranza dentro de las celebraciones jubilares universitarias de Santiago, cuando recordamos la implantación oficial hace veinticinco años de los nuevos estudios de Filología Clásica en Santiago, sin que estas páginas pretendan sustituir trabajos de más fuste que aparecerán pronto ${ }^{3}$. La evocación de Cadaval en estas circunstancias concretas sólo pretende contribuir al conocimiento de un latinista de excepción, pronto olvidado, en la trayectoria humanística de la Universidad santiaguesa.

Las enseñanzas de «Lengua latina, vulgo Gramática ${ }^{4}$, comenzaron siendo siempre las primeras a que se atendía, pues constituían el primer grado y escalón en toda la docencia universitaria. Y de hecho, cuando se constituyó públicamente en Santiago un Colegio de Gramática en 1495, se entendió entonces (y lo fue de hecho) como un primer paso para la Universidad. A partir de tan humildes cunas inició su singladura la Universidad de Santiago que está por ello celebrando solemnemente, como corresponde, sus quinientos años.

Todo parece indicar que en el Colegio de Marzoa, el que funcionó precariamente en el viejo monasterio de San Payo de Antealtares (14951499, quizás 1501), había dos profesores de gramática, uno con rango de Catedrático y otro con título de repetidor. Cuando bastantes años después dispuso de rentas suficientes el Estudio Viejo (fundado por el propio Marzoa, con la ayuda de los dos Diego de Muros, el deán de Santiago y su tío el obispo de Canarias, en 1501), se añadió a los existentes un nuevo Maestro para Medianos, pues la enseñanza de la Gramática, esto es, el Latín, se desarrollaba en tres cursos o grados progresivos, que pueden más o menos identificarse con lo que hace siglo y medio se determinaban como «Rudimentos», «Sintaxis»y «Prosodia», o en la terminología del

\footnotetext{
${ }^{3}$ Se ocupará de él, con abundante documentación inédita, J. Ogando Vázquez que, desde hace muchos años, ha venido reuniendo materiales para su biografía; ha ido dando a conocer diversas noticias en varios trabajos, de alguno de los cuales me aprovecharé en las líneas que siguen. Quiero agradecerle la generosa comunicación, que señalo en su momento, de algunos datos concretos que me han sido sumamente útiles (véase además, en la misma línea de reconocimiento, Couceiro, cit. nota 2, 191).

${ }^{4}$ Tomo emprestada esta fórmula al informe que redacta en 1815 Don Domingo Cortés, Catedrático de la Universidad de Santiago.
}

"CUADERNOS DE ESTUDIOS GALLEGOS", Tomo XLIII, Fascículo 108, Santiago 1996. 
siglo XVI Menores, Medianos y Mayores 5 . Cada uno de estos profesores leía por tres horas diarias, dos por la mañana y una por la tarde. No sabemos en los comienzos qué textos se seguían; pero tenemos la certeza de que en el Estudio Viejo, y debidamente reglamentado, se empleaba el Arte de Antonio de Nebrija. En las clases vespertinas, preferentemente dedicadas a traducciones y versiones, se leían en primer curso las Églogas o la Eneida, y las Epístolas ad familiares de Cicerón. En las denominadas reparaciones, que solían hacerse irregularmente después de la clase de la tarde, se leía siempre una comedia de Terencio. En el curso intermedio, o de Medianos, se seguía como obra teórica la de Nebrija, del que se leía y comentaba el libro cuarto. El último año, es decir en Mayores, se dedicaba buena parte de la mañana a escandir y componer versos; cuando se había avanzado suficientemente en este ejercicio a juicio del profesor, y siempre bajo su inmediata responsabilidad, se estudiaba Retórica, generalmente la ad Herennium ${ }^{6}$. En este curso las lecturas eran Horacio o Salustio, y por la tarde César, Suetonio y el de officiis de Cicerón. Por supuesto que el profesor podía leer además otros autores u obras ${ }^{7}$.

Como maestros de latinidad se elegían habitualmente buenos latinistas, de Santiago o de fuera (las Cátedras se anunciaban, cuando habían de proveerse, en plazos muy breves en Salamanca y Alcalá). En todo caso se esperaban y exigían de su docencia unos buenos resultados. Antes de Cadaval no sabemos mucho de quiénes impartieron estas enseñanzas. Cabeza de León en su obra, tan confusa y desordenada como rica en da-

\footnotetext{
${ }^{5}$ En las Constituciones de 1555 de la Universidad de Santiago, Const. III, se establece que «en la dicha Universidad aya tres cathedras o regencias de Gramatica y latinidad, una de menores, una de medianos y otra de mayores, que leen por la orden y tiempo que por las constituciones de lectura les era señalado y mandado; $y$ al lector de mayores se le de por un año, que se cuenta de sanct Lucas fasta otro sanct Lucas, noventa ducados, y al de medianos ochenta ducados, y al de menores ochenta ducados, pagados en dos pagas...; y mas a todos tres de comer y casa en el Colegio de Gramatica segun esta concertado...» (cf. M ${ }^{\mathrm{a}}$ P. Rodríguez Suárez, op. cit. nota24).

${ }^{6}$ Este modelo pedagógico explica la profusión de poemas y composiciones métricas de toda clase que se resgistran en la producción de los humanistas, frente a los escritos en prosa de más fuste pero menos abundantes. Me refiero, por descontado, a las obras menores, del tipo de epístolas dedicatorias, loas y similares.

${ }^{7}$ Extraigo mucha de esta información, que coincide con la práctica usual en las Universidades de Salamanca y Alcalá, de la obra de Salvador Cabeza de León, a que me refiero a continuación.
}

"CUADERNOS DE ESTUDIOS GALLEGOS", Tomo XLIII, Fascículo 108, Santiago 1996. 
tos $^{8}$, piensa que fueron gramáticos los primeros Rectores del Estudio (Lope Sánchez de Ulloa, Pedro de Valencia, Joaquín Nuñón), de los que nada sabemos, al menos en estos quehaceres.

Don Alvaro de Cadaval Valladares y Sotomayor ${ }^{9}$, nació hacia 1505 en la ciudad de Tuy ${ }^{10}$, Pontevedra, donde vivían sus padres, Juan de Cadaval

${ }^{8}$ Historia de la Universidad de Santiago de Compostela, Santiago, 1946, II, 423427. Son muy válidas y aprovechables las informaciones de Cabeza de León, aunque no siempre aparecen debidamente contrastadas en su obra; mantiene, por lo demás, en la exposición, una inútil e incorrecta polémica implícita con afirmaciones diveregentes de Murguía (cit. nota 2) u otros eruditos gallegos de finales del siglo pasado. Esta constante tensión causa no pocas desviaciones del recto y ponderado proceder del historiador. La obra de Cabeza de León resulta, además, sometida a un método poco claro y difícil de seguir.

${ }^{9}$ Véase arriba nota 2. Una nueva orientación, aún muy incompleta, señalan los estudios de Ogando Vázquez, de los que abre nuevos caminos «La 'Descripción y Geografía de Galicia' del humanista Alvaro de Cadaval«, Boletín Auriense, 5 (1975) 113-126, sobre cuyo contenido volveré luego.

${ }^{10} \mathrm{El}$ argumento principal puede deducirse del nombre que adoptó para sus publicaciones, siguiendo un hábito ya común entre todos los amantes de la antigüedad por este tiempo. Cadaval quiso subrayar y definir este origen con los patronímicos clásicos con que ilustra su apellido, lo que prueba que se sentía orgulloso de su origen. Se llama, en efecto, a sí mismo en un primer momento Cadabalus Gravius, nombre que luego completa para mayor determinación con el término Calydonius, de manera que la adjunción de éste constituye una muestra a su modo de ver de perfecta denominación latina, por el clásico sistema de los tria nomina. Luego todavía llega a añadir Tydensis, como si su nombre facticio tuviera ya entidad propia y peculiar, y hubiera que añadirle la determinación de origen. Todo este proceso puede observarse cómodamente en las indicaciones de autoría de sus distintas ediciones y obras. El primer término proviene del gentilicio Grauii, que Plinio (nat. 4,112) atribuye al pueblo que ocupa la margen derecha del río Miño, en torno a Tuy. Por el contrario, Calydonius es adjetivo derivado del epíteto que corresponde al fundador mítico y epónimo de Tuy. Según las leyendas bajomedievales esta ciudad episcopal y fronteriza sería asentamiento de Tideo, hijo de Diomedes, rey de Calydon (agradezco ciertas precisiones a la Dra. Helena de Carlos Villamarín). De este modo, siguiendo la vieja tradición latina, el praenomen designa el indiviiduo, el nomen es genérico, y luego el cognomen precisa y determina la familia propia. Cadaval, ajustándose al uso establecido entre los humanistas, hace la traslación al plano geográfico, de modo que el nomen figurado representa la comarca o región de origen, y el supuesto cognomen el punto nativo concreto. El hecho de que el praenomen sea pura latinización de Cadaval, significa que así se personalizaba el autor, que entendía que bajo este nombre, tenido por propio, no podía designarse ningún otro, conocido en la república de las letras. Quiero advertir aquí al lector que el primero que había deducido sin más el origen tudense de Cadaval, y precisamente a partir de una interpretación exacta de esta denominación lati-

"CUADERNOS DE ESTUDIOS GALLEGOS", Tomo XLIII, Fascículo 108, Santiago 1996. 
y María Alvarez Barbosa ${ }^{11}$, aquél (o muy probablemente algún antepasado suyo) originario quizás de una aldea de su nombre ${ }^{12}$, no muy alejada de aquella ciudad. Don Alvaro era el último de los cinco hijos del matrimonio $^{13}$. Su familia era hidalga, y con no escasos medios de fortu-

na, fue ya Flórez (cit. nota 2), que a su vez es el primero que lo recuerda como escritor y describe algunas de sus obras, a pesar de que hasta entonces había pasado ignorado. Ahora contamos además con sus propias declaraciones, suficientes, según explícita indicación en el primero de los expedientes a que me referiré varias veces, y que describiré más abajo, y a las deposiciones de varios testigos. Con una vacilación que podría causar embarazo, si no contáramos con testimonios más precisos. junto con los latinos antes explicados, nótese que en las representaciones ante Felipe II (véase nota 84), Cadaval usa siempre la misma expresión inconcreta, diciéndose solamente «del reyno de Galicia»; en cambio, en el primer interrogatorio, pregunta primera, pide que se manifiesten los testigos sobre la veracidad de su afrimación expresa de que es «natural de la ciudad de Tuy»

${ }^{11}$ La casa familiar parece que estaba situada en la calle de Cuenca, según G. Álvarez Limeses, en Geografía general del reino de Galicia, Pontevedra 2, Coruña 1980, 820821; según Avila, cit. nota 2, 256, en la calle «entonces llamada de la Zapatería y ahora de Abajo, en las casas que en ella tenían». Parece que no hay ninguna contradicción entre ambos asertos, pues la calle de Cuenca estaba antiguamente formada por tres que llevaban nombres diferentes, todos ellos gremiales, lo que significa que, aunque ninguna de estas designaciones coincide con la que nos interesa, se hace verosímil que existiera tal calle por la misma zona.

${ }^{12}$ Se ha dicho y repetido que se trata de un lugar de la parroquia de Budiño, municipio de O Porriño, Pontevedra. Pero de nomenclátores y diccionarios geográficos resulta que entre los varios Cadaval existentes en Galicia, el único que puede tomarse en cuenta es un lugar de la parr. de Santiago de Pontellas, ay. de O Porriño, ya citado por Madoz. Algunos de los autores citados anteriormente (véase nota 2) llegan a proponer lugares más distantes, incluso en las cercanías de Lisboa

${ }^{13}$ Es el quinto en el orden de nacimiento, que conocemos por otra documentación sólo marginalmente atingente a nuestro personaje. Los hijos del matrimonio formado por Don Juan Cadaval de Valladares, señor de la casa de Arcos, y Doña María Alvarez Barbosa, señora de la casa de Matamá, fueron: Francisca, que heredó la casa de Arcos; Isabel, monja; Eitor (con otra grafía Héctor), que probablemente murió niño o joven; Pedro, que se quedó con la casa de Matamá; y finalmente Alvaro. En todo caso, como menor de los hijos del matrimonio se explica que haya estado sometido quizás a los particulares cuidados de su hermana Francisca; de aquí el grandísimo afecto que siempre parece haber profesado Don Alvaro a esta hermana suya. cf. J. F. Ogando Vázquez, «Un gallego maestro insigne en Coimbra. Francisco de Caldas Pereira y Castro», Boletín Auriense, 1 (1971) 217-219; especialmente interesante el árbol genealógico de p. 218. Este autor recoge el testimonio del testamento de la madre de Don Alvaro, otorgado en 1549, en que se da otro orden para los hijos por ella tenidos: serían Pedro, Álvaro, Francisca e Isabel; no aparece Héctor, quizás ya fallecido. Parece evidente que este orden tiene otras justificaciones.

"CUADERNOS DE ESTUDIOS GALLEGOS", Tomo XLIII, Fascículo 108, Santiago 1996. 
$\mathrm{na}^{14}$, por lo que mantenía cierto estado social que permitió a algunos de los hermanos de Don Alvaro disponer de posesiones y entroncar con familias de notable poder económico. La familia de su madre tenía relaciones abundantes y de alcurnia en Portugal.

Estas noticias, seguras, contrastan con las lamentaciones, en más de una ocasión, del propio humanista: su familia no contaría con fortuna por cuanto sus bienes le habían sido confiscados a un antepasado suyo por el rey Don Enrique de Trastámara, como partidario y defensor que habría sido del rey Don Pedro ${ }^{15}$. Sus posesiones, a pesar de tales afirmaciones, eran bastantes para una vida familiar digna; pero es posible que en el reparto de los bienes familiares poco haya tocado en suerte a Don Alvaro como hermano menor, desde luego menos de lo que hubiera deseado y esperado.

Por su situación familiar como último de los hermanos, resolvió dedicarse a los estudios ${ }^{16}$. Curiosamente, sin embargo, no abrazó la carrera eclesiástica. Él mismo declara que «hes hombre libre hijodalgo y no tiene muger ni otro embaraço» ${ }^{17}$, aseveración que excluye terminantemente que se le pueda atribuir la condición de clérigo ${ }^{18}$.

\footnotetext{
${ }^{14} \mathrm{Su}$ padre, que era escudero, murió el 5 de junio de 1541 y fue enterrado en sepultura propia en la capilla de San Andrés de la catedral tudense (Avila y Lacueva, I, 257); «dejó a su muerte un muy decente patrimonio de bienes y rentas», escribe Avila ibid., 258 , contra lo que dice Cadaval repetidamente

${ }^{15}$ El propio Cadaval inicia con estas palabras de identificación el tenor del primer interrogatorio que somete al justicia y alcalde de Santiago: «Alvaro de Cadaval Valladares, quarto nieto del ilustre cavallero Suero Banez de Parada, señor de villas y lugares en el obispado de Tuy al qual el rei Don Enrrique tomo todo su estado porque avia seguido las partes del rei don Pedro segun que lo hizo a otros cavalleros». La afirmación es genérica, a juzgar por los documentos correspondientes, pero viene bien a los efectos especiales buscados por Cadaval.

${ }^{16}$ Quizás haya algo de verdad en la afirmación de Cadaval en la primera de las súplicas a Felipe II: «porque soy hidalgo y pobre y por estudiar he gastado lo que tenía».

${ }^{17}$ En la quinta pregunta del segundo interrogatorio del expediente mencionado arriba. Uno de los testigos, Pedro Varela, canónigo-cardenal de la Catedral compostelana, dice que, en efecto, «hes persona libre, soltero y no casado», respondiendo a esta pregunta. De manera similar, el bachiller Paz, médico de Santiago, responde «ques hombre soltero y por casar y libre».

${ }^{18}$ Pero que también presenta sus problemas. Mantuvo, en efecto, relaciones con Lucía Pose de Castroberde, de la que tuvo un hijo, que posteriormente reconoció legalmente Don Alvaro, sin que ni él ni la madre contrajeran nunca matrimonio (Avila y
}

"CUADERNOS DE ESTUDIOS GALLEGOS", Tomo XLIII, Fascículo 108, Santiago 1996. 
La información sobre sus estudios es escasa. Seguramente habrá estado matriculado en la Universidad de Salamanca, a la que solían acudir los gallegos; pero bien podría haber frecuentado cursos y obtenido grados en la de Alcalá. Parece doctrina común entre los estudiosos que se han ocupado de nuestro personaje dar por sentado que cursó y obtuvo sus grados en la propia Universidad de Santiago. Ello sería posible si tuviera solamente el grado de Bachiller ${ }^{19}$, pero Cadaval usa siempre el título de Maestro, con el que es contratado ya en Santiago en 1542. Ni el grado de Maestro ni el de Doctor se obtenía todavía por los años treinta en el Estudio de Compostela ${ }^{20}$. De otra parte, sus amistades portuguesas ${ }^{21}$, sobre todo con el célebre obispo de Braganza Don Julián de Alba, capellán del rey Don Sebastián ${ }^{22}$, nos sugieren la idea de que hubiera podido tener relaciones académicas con algún centro portugués, pues parece probable

Lacueva, I, 253). Este hijo se llamó Don Juan de Cadaval y Sotomayor, y muerto ya su padre incoó expediente de nobleza e hidalguía, en el que declara que sus padres tuvieron además de él otros hijos naturales, de los que no se sabe nada. No los menciona en absoluto en su testamento, que puede verse en Apéndice I.

${ }^{19}$ Avila y Lacueva, 259, escribe: «Siguió este Don Alvaro la carrera literaria, al parecer en la Universidad de Santiago, con tanto aprovechamiento que se hizo muy sabio y docto; graduóse de bachiller en Facultad mayor...». No cabe vacilación en rechazar estas posibilidades por este tiempo para Santiago; las repite Álvarez Limeses, op. cit. nota 11, 821, y Couceiro, 190. Tampoco sé con qué fundamento asevera Matos, op. cit. nota 2, 512 n. 10, que estudió en Salamanca y en Alcalá, aunque me parece razonable dar por buena y probabilísima esta conjetura. Querría hacer notar que un indicio en esta dirección consiste en el conocimiento profundo que tiene de la Gramática de Nebrija, texto seguido en Alcalá. Y aún añadiría que la calidad de su latín y de sus conocimientos literarios obliga a pensar en una Universidad de honda raigambre humanista, como cualquiera de aquellas dos: no parece creible que en Santiago solo hubiera podido alcanzar tal dominio de la lengua, la retórica y la métrica, mostrada tan pronto, como veremos.

${ }^{20}$ Tampoco sabemos cuáles fueron estos estudios, quizás de Artes, a juzgar por su formación (e incluso por el uso permanente que hace del título de Maestro, grado que en la Facultad de Artes equivalía al de Doctor en las restantes Facultades). Sobre sus grados académicos, véase abajo nota 24 .

${ }^{21}$ Incluso posibles relaciones familiares, pues la madre aunque estrechamente relacionada con Vigo como de la casa de Matamá, tenía vinculaciones portuguesas indudables, como anuncia su apellido Barbosa. Algo más que por estudios estuvo entroncado con personajes portugueses.

${ }^{22}$ Véase luego a propósito de esta amistad y de la dedicación de unos trabajos suyos a este personaje, que parece haberlo tenido, al menos en parte, bajo su protección y ayuda.

"CUADERNOS DE ESTUdIOS GALLEGOS", Tomo XLIII, Fascículo 108, Santiago 1996. 
su estancia posterior en medios lusitanos, como Viana do Castelo y Braga. En todo caso, es innegable que sus estudios hubieron de transcurrir en los treinta del siglo diecsiséis ${ }^{23}$.

Por primera vez aparece en la Universidad de Santiago en 1542, cuando entró a prestar sus servicios en ella como Maestro ${ }^{24}$, firmando el correspondiente contrato con el rector del Colegio Lope Sánchez de Ulloa ${ }^{25}$. A pesar de los títulos que pudiera exhibir $\mathrm{Cadaval}^{26}$ (y es evidente su gran

${ }^{23}$ Se trata de una simple conjetura, que estimo verosímil, aunque bien pudiera haber que retraer los años de su formación universitaria a 1525-1535, más o menos.

${ }^{24}$ Avila y Lacueva, 258, nos informa de que en la ejecución del testamento de su madre, en 1551, se habla de Don Alvaro, al que se llama Bachiller, siendo así que en otros varios documentos anteriores se le llama siempre Maestro. Sin duda fue éste su verdadero grado académico. Sin embargo, el problema no queda así resuelto, pues en un documento universitario de 12 setiembre 1551 se le llama también Bachiller «al bachiller Albaro de Cadabal», si bien es verdad que se trata de una notificación notarial por la que se anuncia la reanudación de las clases y restablecimiento de los profesores en sus puestos, anulando así edicto del Claustro de 2 del mismo mes que estableciera la suspensión de clases en el Colegio y Estudio (todo ello en el clima de tensión por los pleitos y diferencias con el Conde de Monterrey). La notificación es hecha por el escribano Gonzalo Puñal. Podría tratarse de un error o descuido de éste, pero el caso es que al restituirse a sus puestos a los profesores se indica que hay tres gramáticos, uno de los cuales es el maestro Juan del Cano, que cobra cien mil maravedís por año; el segundo mencionado es Cadaval: «nonbraron por un año cumplido que corre desde día de san Lucas primero que biene al bachiller Albaro de Cadabal preçetor de medianos e menores con corenta mil maravedís de salario», y designan a «Lorenzo de Paz para que lea de menores como el dicho Albaro de Cadabal repitiendo las dichas leçiones que leyere el dicho Albaro de Cadabal y conferiéndolas con los estudiantes que las tengan bien entendidas y haziendo sus reparaçiones y que se ocupe en ello el mismo tiempo e oras y por el tenor y forma del dicho Alvaro de Cadabal con selario de veinte e çinco mill maravedis por año» ( $\mathrm{M}^{\mathrm{a}} \mathrm{P}$ Rodríguez Suárez, La Universidad de Santiago en el siglo XVI, Santiago 1996 [edición en microficha], doc. $\mathrm{n}^{\circ} 18$ ). La diferencia de salario no puede estar sólo en función de los grados de enseñanza desempeñados, sino que podría tener relación con el grado académico de cada profesor. Pero creo que este problema no impide seguir teniéndolo, como siempre se le ha tenido, por Maestro.

${ }^{25}$ Está bien atestiguado en el Tumbo IX, documento 54, de la Universidad, conservado en el Archivo Universitario de Santiago: se le daría una paga de 70 ducados de oro al año; cf. Cabeza de León, I, 68. Me pregunto si en estadedicación universitaria no habrá tenido su parte la muerte de su padre, ocurrida el año anterior: véase arriba nota 14

${ }^{26}$ Véase la nota 24 . Antes de 1535 no consta en ninguna parte que se hubieran otorgado grados mayores en los Centros compostelanos; quizás haya sido alguna de estas razones la que ha inducido, pienso que erróneamente, a muchos (por ejemplo, a Carreras Candi, al que copian otros) a sostener que era graduado en Leyes, primera de las enseñanzas que se dieron sistemáticamente correspondiendo a Facultades mayores. Pero es difícil de creer.

"CUADERNOS DE ESTUDIOS GALLEGOS", Tomo XLIII, Fascículo 108, Santiago 1996. 
formación latina ya para entonces), pienso que debió contar para su contrato compostelano con el padrinazgo del influyente Sánchez de Ulloa. Sólo así se explica que a poco de llegar a la Universidad sea encargado de componer un epígrafe de tanta responsabilidad como la inscripción latina del friso del claustro del Colegio de Fonseca de Santiago, edificio recién rematado, y que en este solemne letrero conceda tanto espacio y reúna tantos elementos para adular a Ulloa ${ }^{27}$.

Obtenida la cátedra, la desempeñó quizás por unos veinte años, gracias a haber obtenido del Claustro varias prórrogas, sin que sepamos cuántas ni su tiempo preciso ${ }^{28}$. Hay que recordar que una vez que se obtenía

${ }^{27}$ La que debería dedicarse inequívoca y completamente al recuerdo y la loa de Don Alonso de Fonseca, arzobispo de Santiago y fundador del Colegio y Universidad, que sufragó las obras y cedió el solar en que éste se construyó, dedica una parte del texto y buena parte de los versos a Don Lope Sánchez de Ulloa, arcediano de Reina (viejo título en el cabildo de Santiago que correspondía a una pequeña propiedad de la mitra compostelana en el sur de Extremadura), Rector del Colegio, y albacea testamentario de Fonseca, encargado de llevar a buen término la obra arquitectónica del Colegio. Avanzo mi sospecha, que explicaré luego, de que las frases dedicadas a Ulloa en la inscripción, y los tres versos del epigrama que se refieren a éste, fueron compuestos de manera que pudieran ser eliminados sin detrimento del resto de cada piececilla, en el caso de que parecieran inoportunos o indiscretos; pero no lo fueron, con lo que nuestra sospecha parece afianzarse de que responden a un deseo personal de encomio del personaje Ulloa, que se habrá sentido satisfecho de la benevolencia del latinista. Incluso se puede pensar que los lectores normales, aunque encontraran excesivo el elogio, lo admitirían por el rango de Lope Sánchez, el parentesco con Don Alfonso de Fonseca, y su admirable empeño en ejecutar las disposiciones y buenos deseos de éste.

${ }^{28}$ Afirma él mismo que «a llebado por dos vezes catredas en el Colegio por oposeçion y otras vezes por el claustro, y a leido mas de veynte años con toda delixençia y cuidado dentro del Colegio», afirmación que pone al juicio de los testigos en la primera de las informaciones mencionadas. Tal aserción puede verse ahora confirmada, al tener noticia fidedigna de su oposición y contrato en 1542 y en 1568 (véase abajo nota 32), y queda corroborada en parte por sus frases en la segunda súplica al rey Felipe («ha mas de treynta años que leo en el Colegio y Universidad de Santiago adonde hize mucho probecho con mi trabajo y doctrina y por ser la cathedra trienal ... no me iubilaron aviendome de iubilar despues de aver leydo veynte años, segun hes costumbre de otras universidades») da la impresión de ser hiperbólica y redondeada. La cuentas no cuadran, si es verdad que lee Latín por vez primera cuando gana su primera cátedra en 1542 . Nuevas dificultades comporta su bien documentada estancia en Orense, y las menos acreditadas de Viana do Castelo y Braga: podrían haber sido anteriores a su oposición a la cátedra de Santiago. Pero ciertamente se insertan entre desempeños universitarios en Compostela sus estancias en Portugal, atestiguadas por las ediciones y sus devaneos en los altos círculos cortesanos portugueses.

"CUADERNOS DE ESTUDIOS GALLEGOS", Tomo XLIII, Fascículo 108, Santiago 1996. 
por oposición una Cátedra, no se contaba por ello con contrato vitalicio; al menos no era ésta la costumbre en las plazas de profesor de Gramática, cuyo estatuto universitario difería no poco de las Cátedras de Facultades mayore ${ }^{29}$. La continuidad del profesor dependía en buena parte de su eficacia, pero principalmente de los votos de los personajes que regían la Universidad $^{30}$, que solían prorrogar año a año su misión y fijaban el salario que habría de percibir.

Disponemos de pocas referencias a su persona y actividad en los $\mathrm{Li}$ bros de Claustro universitarios, que se conservan de modo irregular en el Archivo Histórico Universitario de Santiago. En setiembre de 1568 opositó por segunda vez a una cátedra de Gramática el Maestro Cadaval. Se conserva el acta de Claustro en que se resume esta oposición y sus resultados. Merece la pena que nos entretengamos un momento con este episodio de su vida, que estimamos relevante: contendieron dos opositores que contaban, sin duda, con posturas previas de los juzgadores. Gana reñidamente Cadaval, que ve su triunfo limitado por unas reservas que le imponen los señores del Claustro ${ }^{31}$. Se le advierte solemnemente, como

${ }^{29}$ No es necesario recordar al lector que el estatuto de Artes había perdido mucho de su antigua condición y prestigio, habiéndose convertido al correr de los tiempos, desde el siglo XIV sobre todo, en una especie de simples estudios propedéuticos, que la reacción humanista no logró restituir a su puesto preeminente de los comienzos de la institución universitaria.

${ }^{30}$ En Santiago solían ser unas doce personas, entre las que estaba el Rector, generalmente una dignidad del Cabildo, el Visitador, dos canónigos consiliarios, los superiores de San Francisco, de Conjo, de Santo Domingo, el Rector del Colegio de Fonseca, y cuatro catedráticos.

${ }^{31}$ He aquí la parte más importante del acta claustral correspondiente: reunidos para «prober la catreda de Medianos que estaba baca en el Colegio de San Geronimo a que estaban opuestos el maestro Cadabal y el bachiller Martínez, despues de aber leydo sus liçiones de oposiçion que les abian sido señaladas y abiendoseles dado hescrito los nombres de los tales opositores y preguntado a los tales opositores si tenian algo que dezir y alegar sobre la dicha probision, los dichos señores secretamente hecharon sus botos en los cantaros que para ello hay, y despues de aber todos ellos botado salio el dicho Alvaro de Cadaval con ocho botos y el dicho bachiller Martínez con quatro, por manera que el dicho maestro Cadabal abia llebado la mayor parte de los botos le dieron la dicha catreda de Medianos y consta por tres años, que començasen a contar desde el primero de octubre primero venidero de este presente año en adelante, la qual le daban con condiçion que si paresçiese a contentamiento de sus mercedes y a probecho de los estudiantes fuese en su mano de ellos de remobersela pagandole porrata [f. 355] el tienpo que ubiese serbido para lo qual se llamo al dicho maestro Cadabal y se le leyo por delante la dicha

"CUADERNOS DE ESTUDIOS GALLEGOS", Tomo XLIII, Fascículo 108, Santiago 1996. 
expresan las propias palabras del Acta Claustral, que se le retiraría la concesión si no enseñara a satisfacción del Claustro. El resultado de la propia oposición, a pesar del triunfo de Cadaval, ya resulta sospechoso tratándose de un maestro de su prestigio, experiencia y renombre; pero parece aún más sorprendente tamaña cautela, en la que quizás haya que ver, entre otros motivos menos confesables, una especie de desquite por haber abandonado esta Universidad para tratar de medrar fuera de ella. Pese a tanta reserva, no debió de haber motivos de queja suficientes para resolverle la cátedra. Pero los hechos siguen ahí inquietándonos no poco, y obligándonos a preguntarnos cuál sería el trasfoondo de estos comportamientos.

Pero en lugar de los tres años previstos, la cátedra fue objeto de nueva provisión dos años después. Acaso es en los años en torno a 1570, cuando disponemos de más informaciones claustrales sobre nuestro personaje. Éstas acusan un trato ordinario, irrelevante, casi desconsiderado, con el Maestro Cadaval, cuya situación nunca debió ser distinguida. En abril de 1570 se pagan sus fianzas con cargo a la parte que le toca del sueldo de su cátedra; en octubre del mismo año se le pagan atrasos adeudados; en noviembre de este año, en fin, se le concede prórroga de «la catreda de Medianos con el salario que la dicha catreda tiene». A 22 de marzo de 1571 se le concede el pago del salario anual todo junto que le correspondía después de la prórroga del otoño anterior.

El último momento importante de la vida de Cadaval en la comunidad universitaria, acaso el segundo desde su incorporación a la docencia y la redacción de la inscripción del Colegio de Santiago Alfeo por los cuarenta, tuvo lugar en el otoño de 1571. El día de san Lucas fue encargado por la Universidad de pronunciar la oración de esa fiesta, trabajo especial por el que el Claustro acuerda concederle una gratificación de seis ducados en diciembre de ese año. Acaso tal distinción fue un poco su despedida universitaria, ya que concluido ese curso ya no vuelve a aparecer el Maestro Cadaval en sus registros ${ }^{32}$.

heleçion con la dicha condiçion, el qual dixo que con ella la açetaba la dicha catreda y ansi lo prometio de lo cunplir y con esto los dichos señores le mandaron dar el salario de la dicha catreda». La cita es larga, pero refleja debidamente las circunstancias y el tono de una oposición, y la situación del Maestro Cadaval.

${ }^{32}$ Para todas estas noticias, hasta ahora inéditas, me valgo de las trascripciones de los Libros de Claustro hechas por Rodríguez Suárez (véase nota 24).

"CUADERNOS DE ESTUDIOS GALLEGOS", Tomo XLIII, Fascículo 108, Santiago 1996 
En efecto, desde el verano de 1571 desaparece de la documentación universitaria compostelana. En 1572 ya no figura su nombre entre los tres nombres distintos que ocupan las tres cátedras de Latinidad. Deducimos que hacia mediados de 1571 abandonó la docencia universitaria. Es probable que al fin hubiera obtenido la jubilación que había solicitado del rey a finales de 1569 en la segunda de sus súplicas, elevada desde la Corte, a la que en medio de achaques y gastos cuantiosos, según dice, se había trasladado por su cuenta para presentar de cerca sus peticiones a la Corona. Probablemente le fue concedida a Cadaval la merced real cuando concluía la prórroga de su cátedra que, como queda dicho, tuvo lugar en 1570 .

Volvamos un poco atrás. No sabemos por qué caminos (acaso relacionados con la familia de su madre) alcanzó el favor de Don Rodrigo Pinheiro, obispo de Porto, a través del cual intentó convertirse en ayo y maestro del infante Don Antonio, hijo de Don Luis de Portugal. Toda esta actividad en Portugal debió realizarse en frecuentes estancias cortas en aquellas tierras, donde contó con grandes y excelentes amigos, algunos de los cuales no le fueron en todo momento fieles ${ }^{33}$.

Se puede dar por descontado que se encontraría en Lisboa cuando allí se había llevado a cabo a mediados de 1563 la edición de varias de sus obras en los talleres del colonés Blasvio. Volvió en 1565, quizás después de haber estado en Braga, pues a fines de este año y comienzos del siguiente se encontraba de nuevo en Lisboa ${ }^{34}$. Su gran objetivo en esta oca-

\footnotetext{
${ }^{33}$ Entre sus amigos, cuenta L. de Matos (cit. nota 2) a Joâo Ruiz de Sá de Meneses, Pedro Andrade Caminha y Fernando Oliveira. Elogia y considera amigos suyos a Diogo Teive y Marcial de Gouveia, así como a Jeónimo Osório. Claro es que casi todos estos nombres aparecen en obrillas suyas, y al referirse a ellos acaso estaría haciendo no tanto demostración de verdadera amistad como quizás mejor ejercicio de captatio benivolentiae.

${ }^{34}$ Se tienen noticias de que en 1565 y 1566 se enfrentó con graves problemas con la Inquisición portuguesa, aunque las acusaciones vertidas contra él quizás carecían de fundamento toda vez que se vio libre de este proceso y pudo retornar en breve a España, donde estaba ya en 1568; cf. Matos, 512 n. 10. Pienso si motivo de este encausamiento inquisitorial no habrá sido precisamente su devoción por Marcial de Gouveia, alabado en la primera edición de su tratado De obitu ... Ioannis tertii, y sustituido luego en la segunda. En todo caso, no cabe la menor duda de que el proceso inquisitorial no le causó mayores problemas, porque no sólo volvió a España, sino que pudo opositar nuevamente a la cátedra de Medianos de Santiago. Por otra parte, en los testimonios jurados con que responden a su encuesta los testigos de las informaciones de 1569, varios de éstos lo declaran positivamente buen católico.
}

"CUADERNOS DE ESTUDIOS GALLEGOS", Tomo XLIII, Fascículo 108, Santiago 1996. 
sión era entrar al servicio, como he dicho, del infante Don Antonio, por lo que aumentó por estos tiempos el número de sus poemas y dedicatorias a diversos miembros, siempre muy encumbrados, de la familia real portuguesa. Pero no consiguió sus propósitos. En todo caso debió quedarse bastante complacido por haber alcanzado la protección suficiente del Cardenal-Infante Don Henrique para que fueran editadas sus obras (y dos al menos reeditadas) en Lisboa entre 1565 y 1568 . La verdad es que nunca llegó a aparecer impresa ninguna obra suya fuera de las editadas por estos años en Lisboa.

En varias ocasiones se nos habla de que había ejercido docencia en diversas Universidades, sin que nos sea posible averiguar en tal caso si se había estrenado en alguna parte antes de la llegada a Santiago, o si siempre enseñó en esos puntos en alguno de los intervalos de sus estancias aquí ${ }^{35}$. De las docencias no compostelanas de que tenemos noticia la única bien documentada es la que desempeñó en Orense, quizás a título privado. No sabemos cuánto duró. Probablemente se convirtió en ayo, pagado por una familia distinguida, para cuidar de la enseñanza y educación de algún muchacho. Lo cierto es que logró sacar algún discípulo tan aventajado que fue capaz de hacer armas poéticas, que estimó dignas el propio $\mathrm{Cadaval}^{36}$. También por referencias propias, poco precisas, sabemos que ejerció, quizás de la misma manera, en Braga.

\footnotetext{
${ }^{35}$ Él mismo deja entrever que enseñó en otros lugares además de Santiago, sin que podamos fehacientemente saber cuáles fueron éstos, al menos por el momento. Según una nota del propio autor en la portada de sus comentarios al libro cuarto de Nebrija, que mencionaremos luego, fueron leídos por vez primera en Orense. También uno de los testigos, el bachiller Antonio Rodriguez de Leis, vecino de Santiago, declara que es «cathedratico en el Colegio e Universidad de Santiago de Galiçia y lo fue ansimismo en otras partes y lugares». ¿Podrá deducirse de aquí que se está pensando en alguna enseñanza en territorio portugués? Recordemos que Cadaval se mueve en este terreno siempre con términos imprecisos, sobre todo en España, y parece que menos recatado en Portugal. Por otro lado, como he señalado, ejerció docencia en Orense (abajo, nota 66, menciono incluso el nombre de un discípulo suyo orensano). pero acaso en forma privada, carácter que quizá también tuvo su enseñanza en Viana do Castelo (si pudiera confirmarse). Desde luego parece posible afirmar que no ejerció en ningún otro centro universitario fuera de Santiago.

${ }^{36}$ Remito a la descripción de las obras impresas más adelante, porque allí menciono algunas piezas interesantes en este argumento.
}

"CUADERNOS DE ESTUDIOS GALLEGOS", Tomo XLIII, Fascículo 108, Santiago 1996. 
Podemos dar por sentado que poco después de jubilado cayó enfermo, en una especie de demencia senil que acabó haciéndose aguda (lo que un documento referente a nuestro personaje, unos años posterior, debido a su sobrino Caldas Pereira, describe con precisos síntomas, y denomina «phrenessi» ${ }^{37}$ ). El proceso no hizo sino agravarse hasta que falleció en el barrio de Mazarelos de Santiago, extramuros de la ciudad ${ }^{38}$, el día 9, o más probablemente el 10 de marzo de 1575 . Según disposición testamentaria debería ser sepultado en Tuy, en la Catedral, que él designa bajo el título de su dedicación a Nuestra Señora. Mantenía así el afecto a su ciudad natal. Pero como dejó poder al respecto a su «cumplidor», en este caso Suárez de Tangil, el canónigo resolvió que se le diera sepultura en la iglesia de Santa María la Nueva de Santiago ${ }^{39}$

\footnotetext{
${ }^{37}$ Merece la pena conocer la descripción de la enfermedad, muy exacta aunque pudiera haber exageración en ciertros detalles visto el objetivo del documento en que se encuentra: «estando assi doente na cidade de Santiago, o cónego Soarez seu amigo et olim discipulo o levou pora sua casa onde estándose curando e crescendo a infirmidade lhe sobreviu phrenessi, de que esteve fora de seu juizo e entendimento alguns dias antes de seu falescimento e levantándose da cama e descubríndose e vacilando con a memoria o sentido fallando e dezendo muitas palavras fora de propósito e facendo muitos desatinos, como homem alienado de seu juizo, estando assi atribulado de phrenessi» (del informe preparado por Caldas para impugnar el testamento de Cadaval: lo tomo de Ogando, art. cit. nota 13, 220).

${ }^{38}$ Parece que habría que situar este barrio en el terreno hoy ocupado por el Convento de Mercedarias, limitado quizás por el Castrondouro y el Pexigo. Pero no tengo datos seguros.

${ }^{39}$ Esta iglesia, situada intramuros, en la actual Plaza de Mazarelos; ocupaba prácticamente el solar de la Casa de Ejercitantes de los Jesuitas, actualmente edificio universitario. La prueba definitiva de este enterramiento lo tenemos en un documento conservado en Santiago, Arch. Cat. Varia $1^{\text {a }}$ parte, Tomo III, f. 394v: «En la ciudad de Santiago a honze dias del mes de março de mill y quinientos e setenta y cinco años por delante de mi notario y testigos Juan Carron, criado del monasterio de Santa Maria la Nueba de la dicha çiudad, se dio por entrego y pago del señor canonigo Diego Xuarez de Tangil como conplidor del anima y testamentario del dicho poheta Cadabal por razon de su sepultura y deposito que se a fecho en el dicho monasterio del dicho difunto y por se le azer al el ofiçio de todo ello se a pago al dicho monasterio quarenta y çinco reales de los quales se dio por entrego y al sobredicho por libre dellos. Y dello otorgo carta de pago e rogo a Juan Perez lo firme.-Testigos el dicho y Juan de Rosende e Bartolome Martinez.Juan Pérez (rubricado).- Paso ante mi Gonzalo de Regeira /rubricado)».
}

"CUADERNOS DE ESTUDIOS GALLEGOS", Tomo XLIII, Fascículo 108, Santiago 1996. 
En los últimos tiempos de su vida lo asistió un canónigo compostelano, el Diego Suárez de Tangi ${ }^{40}$ recién mentado, al que cinco días antes de su muerte había convertido en su heredero universal. No sabemos cómo llegó a conocer los hechos su familia, que resolvió impugnar el testamento basándose precisamente en las precarias condiciones mentales de Don Alvaro $^{41}$. Razones no le faltaban, si mereciera la pena, porque a pesar del testimonio del notario y de los testigos presentes que signan el documento, el estado de nuestro personaje se descubre fácilmente con sólo contemplar cómo le faltaban fuerzas y cabeza para poner todo su nombre en la firma que debería convalidar el testamento. Es verdad que en él disponía en favor de Tangil incluso los bienes que le pudieran haber tocado por herencia, punto sensible para los suyos; pero todo sumado representaban bien poco, a juzgar por lo mísero de su legado.

Podemos leer el Inventario de los bienes dejados a su muerte por $\mathrm{Cadaval}^{42}$, que revela, en efecto, si no una pobreza mayúscula, al menos

\footnotetext{
${ }^{40}$ No quiero ocultar la sospecha de que en la amistad con este canónigo haya una clave importante de la situación de Cadaval. Creo, en efecto, que Suárez de Tangil, o su familia, debió de gozar de la confianza del arzobispo Fonseca, como se colige del hecho de que fuera incluso depositario de una copia del testamento de aquél (cf. López Ferreiro, Historia de la Santa ... Iglesia de Santiago, VIII, Santiago 1904, ap. p. 86); más aún, este personaje es uno de los hombres fuertes de la Universidad de Santiago, en la que siempre tuvo mucho poder. Si se diera el padrinazgo que he conjeturado de Lope de Ulloa y la amistad con Suárez de Tangil fuera antigua (acaso favorecida por haber sido discípulo universitario del propio Cadaval), bien pudieran ambas circunstancias constituir el ambiente que llamaríamos fonsecano en que se movía Cadaval, quizás bastante para explicar mucho de su situación (ayudada por su propia manera de ser) universitaria, y aún compostelana. De todos modos, además de este precedente fonsecano de la personalidad de Suárez de Tangil, no hay que olvidar que se tenía a éste por fiel y adicto discípulo de Cadaval (véase el texto trascrito en nota 38).

${ }^{41} \mathrm{La}$ impugnación del testamento, precedida de una serie de noticias de las que extraigo los datos anteriores, se debe, como queda dicho, a un sobrino del propio Cadaval, insigne maestro de Derecho (en la cátedra de Digesto viejo) en la Universidad de Coimbra, cuyos principales puntos biográficos reconstruye Ogando Vázquez, art. cit. nota 13. Caldas Pereira, hijo de Doña Francisca, la hermana mayor del maestro Cadaval, preparó el expediente, que quizás no llegó a presentarse judicialmente cuando se comprobó la poca calidad de los bienes dejados por Cadaval a su muerte. Quiero a este respecto remitir al lector a la lectura del Inventario de sus bienes que figura en el Apéndice de estas páginas.

${ }^{42}$ Utilizo la transcripción que aparece en el Apéndice, que puedo editar gracias a la generosa actitud y permiso de D. José María Díaz Fernández, Canónigo Archivero de Santiago, al que una vez más expreso mi reconocimiento; la lectura de todos los docu-
}

"CUADERNOS DE ESTUDIOS GALLEGOS", Tomo XLIII, Fascículo 108, Santiago 1996. 
una falta total de propiedades valiosas. Entre ellas se menciona «otra arca de libros en la que se alló los libros siguientes», que se enuncian por los sistemas usuales en aquel tiempo con graves y a veces insalvables problemas de correcta identificación. Como era de esperar en el contenido de un arca, no se encuentra ningún principio clasificatorio. La librería resultante aparece integrada por solos 81 volúmenes, sin que se pueda observar la presencia de obras bien conocidas por Cadaval, puesto que las había utilizado en sus propias producciones ${ }^{43}$.

De lo poco que le quedaba cuando se hace el Inventario, deducimos que dominan con mucho en él las preocupaciones por los antiguos escritores latinos, singularmente poetas, con presencia significativa de autores griegos. Además de las gramáticas y obras similares ${ }^{44}$, creo conveniente llamar la atención sobre la que él prestaba a colecciones de poemas, tanto en forma de antologías como en forma de producciones propias de algunos autores, clásicos y contemporáneos suyos ${ }^{45}$. No aparecen en su biblioteca más que unas cuantas obras que pudiéramos denominar laxamente de carácter eclesiástico ${ }^{46}$. Sin dificultad sospechamos que su triste experiencia portuguesa con la Inquisición le había enseñado a ser cauto; acaso

mentos pertinentes que se guardan en la Catedral de Santiago fue hecha por Ma Pilar Rodríguez Suárez, cuyos valiosos servicios agradezco vivamente. También edito, como puede verse, el testamento del Maestro Cadaval. Me parece que así presto un buen servicio a la comunidad científica, toda vez que la edición anterior, debida a Antonio López Ferreiro, fue publicada en el folletón de una revista en 1908, que se cita a menudo sin las debidas especiificaciones, por lo que confieso que he sido incapaz de localizarla en las Bibliotecas que he consultado. Curiosamente tampoco aparece registrada en ninguna de las bibliografías de este personaje compostelano, en singular en la elaborada por $\mathrm{M}^{\mathrm{a}}$. $\mathrm{P}$. Sánchez-Cantón Lénard, «Apuntes para la biografía de Don Antonio López Ferreiro», Cuadernos de Estudios Gallegos, 15 (1960) 294-312, base de todas las que se han publicado luego.

${ }^{43}$ No quiero entrar aquí en mayores detalles que no son de este lugar. Espero que pronto Ogando Vázquez nos dé justificadamente cuantas identificaciones haya sido capaz de hacer. Confieso que por un momento me tentó ocuparme de la cuestión, pero requiere mucho tiempo y paciencia, que no son mi patrimonio ahora.

${ }^{44}$ Piénsese en las varias Artes de Nebrija, en la Arte hebrea de Pagnines, en las Artes griegas, en el Calepino, en el Lexicon, y en Clenardo. En esta línea aparecen varias Ortografías, inclusa una griega.

${ }^{45}$ Horacio, Catulo, Marcial, junto a Flores epigrammatum, a las Silvae nuptiales de Nevizano o las Parténicas de Bautista Mantuano.

${ }^{46}$ Una Biblia, un Confesonario, un Breviario, Ferrara sobre los Salmos, y poco más.

"CUADERNOS DE ESTUdIOS GALLEGOS", Tomo XLIII, Fascículo 108, Santiago 1996. 
es ésta la razón de que en su librería aparezca el Índice de libros prohibidos, pieza entonces muy importante, singularmente cuando se habían tenido problemas con el Santo Tribunal. Su experiencia docente le llevó a apreciar el valor de los libros en romance, por lo que se encuentran no pocos entre los suyos, a veces con versiones de autores clásicos.

Cuando se quiere comprender la verdadera situación de Cadaval, hay que comenzar por discutir (lo que sería importantísimo si contáramos con suficiente información para ello), sus relaciones con el Claustro y Universidad de Santiago. Pero no es posible adentrarnos en esta cuestión mientras no se disponga de más documentos que nos lo aclaren, por una u otra parte. Pues el hecho es que sorprende grandemente que, cuando hacia el final de su vida solicita las dos informaciones para elevar al Rey Felipe en función de su proyecto de Geografía del Reino de Galicia, no haga figurar entre los declarantes más que a un profesor universitario, y aún diría que ello sin atender a esta condición. Podría explicarse este hecho de múltiples maneras; pero no así otras situaciones. ¿Qué tipo de inquina o recelos había despertado su nombramiento primero, y su comportamiento después? ¿Se remontarán tales actitudes al hecho de que en 1542 lo hubiera contratado como Catedrático de Gramática el entonces Rector Lope Sánchez de Ulloa?

Lo que parece cierto es que sus supuestos problemas con la Inquisición no le afectaron posteriormente. Por esta razón, ya que no quedaron secuelas de tal situación, tenemos que volver ahora a preguntarnos cómo es posible que, después de más de 20 años por lo menos de relación con la Universidad, se le imponga la dura reserva, de que hice mención al hablar de su oposición de 1568. No deja también de maravillar que en la únca obra que es innegablemente consecuencia de su docencia universitaria, a saber, el Comentario al Libro Cuarto de Nebrija, recuerde su explicación en Orense y no mencione en absoluto la compostelana, donde precisamente venía obligado como Catedrático de Medianos a leer y comentar con regularidad, año tras año, este libro nebrisense ${ }^{47}$. Más aún, ¿cómo es posible que en la titulación del testamento no se mencione de ninguna manera su condición de profesor de la Universidad? ¿Hubo por su parte

${ }^{47}$ Sólo encuentro como posible explicación que sus amistades orensanas hayan sido las que le facilitaron las relaciones portuguesas subsiguientes. Pero no parece que así se justifique todo.

"CUADERNOS DE ESTUDIOS GALLEGOS", Tomo XLIII, Fascículo 108, Santiago 1996. 
una especie de renuncia al pasado que llevó a que en varias ocasiones, al tiempo de su enfermedad y muerte, se le denomine «poeta» en lugar de Maestro?

Hombre soberbio y vanidoso, quizás fosco y ligeramente misántropo, reacio a mantener relaciones con gentes que él no consideraba superiores, aspiraba sólo a amistades con grandes personajes, de las que gustaba luego alardear con mayor o menor fundamento ${ }^{48}$. Tuvieron que ser muy fuertes las razones, sin duda de discreción política, que lo movieron a silenciar ante el Rey Don Felipe algunas de sus relaciones de amistad y servicio a miembros de la familia real portuguesa, así como su actitud lisonjera con ésta en las dedicatorias, poemas y obras consagradas al rey Don Sebastián, al rey Don Juan, al infante Don Antonio, y a la princesa Doña María; pero no dejan de sorprendernos dada la actitud por este tiempo del rey Felipe. En la misma línea hay que añadir su silencio respecto a los insignes Prelados Don Julián de Alba, Obispo de Braganza, y Don Rodrigo Pinheiro, Obispo de Porto, al que en todo momento se siente sincera y hondamente agradecido. Lo cierto es que, por unas u otras conveniencias, su silencio es total respecto a la mayor parte de estos personajes, y a los servicios que aparentemente les había prestado. Silencio también sobre lo más importante de su vida universitaria. Hay que convenir que el talante del Maestro Cadaval no puede presentarse como modelo humano.

Este engreimiento fundamental, que arranca ciertamente de su capacidad intelectual indiscutible, de la que tenía el más amplio concepto, se observa de manera debida en el tenor de una de las preguntas que dirige

${ }^{48}$ Es curioso reproducir a este respecto la pregunta $1^{\mathrm{a}}$ que formula en su primer interrogatorio. Dice así: «sean preguntados los testigos si conosçen al dicho maestro... por buen christiano catholico y por hijo dalgo notorio y por hombre bien criado, afable, de buena y onesta conversaçion, honrrado, estudioso, de buen engenio, memoria, entendimiento y juizio y amigo de toda virtud». Pero todavía me parece mucho más representativa la tercera pregunta, formulada así: «digan los testigos si saven quel dicho maestro... hes conosçido de reis, prinçipes y grandes señores, perlados y letrados por hombre entendido, prudente y doto, hespeçial del rei y reina de Portugal y del ynfante cardenal don Enrrique e ynfanta doña María...», y aún en la $6^{\mathrm{a}}$ : «si saven... que...se trato siempre y bivio como hombre honrrado e hijodalgo, acompañando siempre con presonas principales... y siempre enseño los hijos de los governadores y oidores desde reino de Galicia y siempre compañava y platicava con ellos e yba muchas veces a sus casas...» A pesar del tono y objetivos del interrogatorio, me parecen frases significativas para diseñar su personalidad.

"CUADERNOS DE ESTUDIOS GALLEGOS", Tomo XLIII, Fascículo 108, Santiago 1996. 
en la primera de las informaciones de 1569 a los futuros testigos: «sean preguntados si saben y es verdad que el dicho maestro Alvaro de Cadaval es uno de los elegantes oradores y poetas latinos que hubo y hay en toda España, muy elocuente y resoluto en todas las historias y antiguallas que son menester para su facultad y profesión, y que escribe tan bien en prosa como en verso latino, lo cual se halla muy pocas veces y es cosa rara $»^{49}$. De todas maneras, hemos de ver en esta suficiencia un rasgo no poco característico de muchos hombres del Renacimiento.

A este sentimiento de superioridad y de afirmación personal atribuyo sin duda el hecho curioso, y no muy frecuente, de que la inscripción del claustro del palacio de Fonseca que él compuso vaya firmada. En efecto, la inscripción remata con la mención del año 1544. Pero luego, en letra de módulo sólo un poco menor, nada menos que horizontalmente sobre las dovelas del último arco del claustro, coincidiendo con el final de la inscripción, aparece la leyenda Cadaval hec, sobre cuya intencionalidad y significado no caben mayores discusiones. La actitud que implica llama la atención, porque se trata a no dudar de su primera obra, datada y firmada. Su situación la vuelve más que ninguna otra puesta ante el público, de manera que no resulta sorprendente que durante mucho tiempo, para muchos, haya sido la única obra conocida de Cadaval, y representativa suya por el lugar y las circunstancias de composición y grabado.

Parece oportuno presentarla aquí, debidamente revisada, para hacer sobre ella unos brevísimos comentarios:

Carolo Caesare cum matre regnantibus ${ }^{50}$ Alfonsus Fonseca illustris antea Compostellanus demum uero Toletanus archipraesul ad decorem patriae et ut studiosi absque sumptu discere possent gimnasium hoc in aui materni aedibus ${ }^{51}$ extruendum curauit. Morte uero praeuentus

${ }^{49}$ Es la segunda de dicho primer interrogatorio.

${ }^{50}$ Se puede observar en la inscripción que se había comenzado inicialmente a grabar el singular regnante, pero luego se enmendó sustituyéndole el plural para mejor registrar la corregencia, que quiso mantener explícitamente la cancillería castellana, por respeto a la reina Doña Juana.

${ }^{51}$ Hay que entenderlo dicho del solar, y quizás de las construcciones en él antes existentes, porque el Colegio de Fonseca es edificio de nueva planta (en que intervienen en grados diversos Domingo de Andrade, Alonso de Covarrubias y Juan de Álava), y en ningún caso funcionó en una casa anterior en el mismo lugar.

"CUADERNOS DE ESTUDIOS GALLEGOS", Tomo XLIII, Fascículo 108, Santiago 1996. 
Lupo Santio de Ulloa archidiacono ${ }^{52}$ rectori perficiendum ex b. testamento ${ }^{53}$ reliquit. Qui obiit pridie Nonas Februarii anno Domini millesimo quingentesimo trigesimo quarto, aetatis quidem suae sexagesimo.

Nunc magis atque magis Gallaecia fulget alumno qui dedit hunc patriae ${ }^{54}$ tantum generosus honorem. Sanctius ipse Lupus propria de stirpe creatus ${ }^{55}$ ut Musis gratum faceret tenebrasque fugaret omnibus hoc breuiter compleuit amabile munus quo populus merito, proceres et concio tota innumeras tanto grates pro lumine reddunt. [1544]. $<$ Cadaual hec $>$

No creo fantasear intolerablemente si pienso que la frase Morte uero praeuentus... testamento reliquit, así como los veros 3-5 (Sanctius ipse... amabile munus) son como una especie de texto inserido en una forma distinta, como destinado solamente a la exaltación personal del Rector López de Ulloa. Me atrevería incluso a decir que, sin tales inclusiones, el texto fluye hasta cierto punto como más suelto y preciso, en el período en

\footnotetext{
${ }^{52}$ Parece como si la abreviatura por embebimiento de este título se hubiera ajustado a última hora. Desde luego en la inscripción no aparece nada que dé pie para pensar que había alguna referencia a la condición del título entre los varios arcedianatos de que disfrutaba la Iglesia compostelana: nada hay que recuerde ni de lejos la forma completa de «arcediano de Reina». Pues, como he señalado a tiempo en la nota 27 , se trata de título anejo a una localidad extremeña, y no tiene nada que ver con ninguna reina nacional ni extranjera, como han entendido algunos eruditos que se esforzaron por dar una versión castellana (o gallega, a partir de la interpretación castellana anterior) de esta inscripción. Tal versión, más o menos oficializada, no pasa de ser en este punto una especie de explicación parafrástica, a veces errada.

${ }^{53}$ No parece muy claro el significado de esta abreviatura. El Prof. Javier D’Ors me dice que hay que excluir la interpretación bonorum testamento, que sería fácil, porque el genitivo que acompaña a menudo a la forma testamento se refiere siempre al otorgante y no a lo poseído. En todo caso puede decirse que la presencia de tal determinación, sea ella la que fuere (acaso una indicación usual en la époco, que no he podido averiguar, de que se trataba de una disposición complementaria, codicilar, o semejante) explica por qué Cadaval se ha visto obligado a escribir la preposición ex, pues en la expresión corriente es más frecuente decir sólo testamento reliquit.

${ }^{54} \mathrm{Se}$ afirma así terminantemente que Fonseca nació en Galicia.

${ }^{55}$ Lope Sánchez de Ulloa estaba emparentado, a través de los Ulloa, con la madre de Alfonso de Fonseca III, también Ulloa, familia procedente de la región de Toro.
}

"CUADERNOS DE ESTUDIOS GALLEGOS", Tomo XLIII, Fascículo 108, Santiago 1996. 
$\operatorname{prosa}^{56}$, e incluso en el poema ${ }^{57}$. En uno y otro caso, se llegaría a la conclusión de que Cadaval compuso con exquisito cuidado y habilidad el texto íntegro, pero como previendo que alguna censura discreta recomendara la supresión de las partes ulloanas, dotó al resto de la cualidad de texto completo y suficiente en sí mismo; pero no ocurrió así, quizás porque el propio arcediano y rector se sintió altamente lisonjeado, no sin razón, con ser presentado de modo tan halagüeño. Quiero recalcar que los hexámetros son buenos, con cesura regular pentemímera ${ }^{58}$, y con excelente prosodia ${ }^{59}$. Nótese además que los autores que le han facilitado ex-

${ }^{56}$ La supresión del párrafo señalado en la parte en prosa, hace que el qui que introduce la última frase se presente adecuadamente situado, sin ningún género de ambigüedades. Es verdad que nada se puede objetar a la mención de la nueva disposición codicilar por la cual encarga Fonseca a Sánchez de Ulloa que remate la construcción. Pero la inscripción resultaría más fonsecana sin este inciso, que produce una inconveniente anfibología en el relativo. De no haberse redactado con el supuesto inciso, sería innecesario este qui, ya que el verbo obiit sigue siendo predicado suficientemente claro del único nominativo del período, que no es ni puede ser otro que el personaje celebrado.

${ }^{57}$ Quizás quiera ver más de lo debido, pero pienso que en el v. 6 quo se refiere con suma naturalidad al honorem anterior. Quedaría así el poema, tal como me parece construido inicialmente: Nunc magis atque magis Gallaecia fulget alumno/ qui dedit hunc patriae tantum generosus honorem/ quo populus merito, proceres et contio total innumeras tanto grates pro lumine reddunt. Se puede objetar una cierta repugnancia a admitir quil $q u o$ en dos versos consecutivos, pero puede haberse buscado un efecto llamativo, y un recurso cómodo, en el inicio del verso, análogo al obtenido por la reiteración tantum/ tanto, en dos versos consecutivos, aplicados a términos diferentes. Si las inclusiones que supongo han sido concebidas desde un principio, aunque probablemente las frases dedicadas a Ulloa podrían haberse insertado de otra manera más integrada poéticamente, se explica el juego tenebras/lumine; sin esta redacción, el poeta crearía en torno al Colegio y Universidad una atmósfera especial, que vendría dada por fulget y lumine, al comienzo y al fin del poema. En todo caso, la habilidad del poeta ha consistido en presentar la forma en prosa y los versos de manera que se podría en la lectura prescindir de los incisos sin menoscabo de la composición general. Por supuesto, no querría llevar a una posición extremada mi conjetura de la inserción, que presento solamente como una posibilidad digna de nota.

${ }^{58}$ Se exceptúa solamente el v. 4 que la lleva heptemímera.

${ }^{59}$ Se nota como una especie de obsesión por mostrar que oclusiva más $r$ no hace nunca posición (patriae, propria, creatus, tenebrasque). La condición prosódica se observa bien en la excelente medida de proceres, con su antiquísima larga final. Nótese asimismo la habilidad con que inserta la primera parte del nombre de Ulloa.

"CUADERNOS DE ESTUDIOS GALLEGOS", Tomo XLIII, Fascículo 108, Santiago 1996. 
presiones, que usa especialmente en algunas posiciones del verso, son muchos y muy representativos ${ }^{60}$. Bella leyenda en admirable edificio ${ }^{61}$.

Las obras que Cadaval recuerda expresamente para que los testigos por él citados depongan ante el notario si las conocen y cuál pueda ser su valor, son las siguientes ${ }^{62}$ : «[1] la Sintaxis de las partes de la oraçión al rey don Sebastián; [2] la Apotheosis del rei don Juan el terçero con [3] el planto de la reina doña Catalina a la misma reina; y [4] el Universal Dilubio que aconteçió en el tiempo del gran patriarcha Noee en verso heroico, dirigido al dicho cardenal don Henrrique; y [5] la Brachilogia intitulada al señor don Duarte en prosa y verso latino heroico y elegíaco; y [6] la Recomendaçión de la Arte Poética al señor don Antonio; y [7] la

\footnotetext{
${ }^{60}$ Me refiero exclusivamente a unas cuantas frases, con preferencia a las cláusulas, porque esta posición se prestaba muy bien a inspirarse en buenos escritores. Para v. 1 resulta tentador relacionar parte de la expresión con Verg. Aen. 6, 877 ullo se tantum tellus iactabit alumno; análogamente, con relación remota, pero interesante. Piénsese para 2 en Prop. 4, 11, 61 generosos uestis honores.- La cláusula de v. 3 es de comparar con Ov. met. 14, 699 humili de stirpe creatus (también cercano Lucr. 1, 733 stirpe creatus = Verg. Aen. 10, 543).- Verso 5: paralelos significativos y brillantes son Ov. met. 14, 225 memorabile munus, y Ov. ars 2, 723 amabile murmur.- Verso 7 recuerda Ov. Pont. 1, 1, 57 lumina reddunt. Este probado regusto por los autores más distinguidos se observa en otros casos: recuerdo, por ejemplo, que magis atque magis del v. 1 depende de Verg. Arn. 2, 299; tenebrasque fugaret de v. 4 es una buena cláusula, que evoca la expresión de Hor. carm. 4, 4, 39 fugatis ille dies Latio tenebris.

${ }^{61}$ ¿Por qué Cadaval nunca incluyó este bello epigrama en alguna de sus ediciones posteriores? Entre las varias razones que podrían aducirse para explicar este hecho (que no puede deberse en absoluto a que él estimara en poco esta bella composición), acaso la única admisible es que, haciéndose las impresiones de las restantes en Lisboa, y dependiendo para ellas de la generosidad del Cardenal Don Henrique, no querría presentar allí una pieza compostelana, en honor de unos personajes que nada tienen que ver con el ambiente portugués en que se mueve. Esta reacción y actitud me parece que están en la misma línea que algunas otras que ya he comentado.

${ }^{62}$ Mantengo estrictamente la forma dada en la copia notarial que para en Simancas. Me ha parecido oportuno añadir un número para que se pueda establecer relación con los impresos que enumero a continuación. Cadaval utiliza sus recuerdos personales de las obras editadas filtrándolos de acuerdo con sus intereses coyunturales. De todos modos, no deja de ser sorprendente que no recuerde en ningún momento tan preciosa inscripción como es el texto del Colegio de Fonseca, sobre el que habrían podido pronunciarse adecuadamente los testigos invocados. A no ser que haya preferido limitarse a obras publicadas en la imprenta, porque ellas suponían un reconocimiento diríamos más universal y más trascendente para su persona.
}

"CUADERNOS DE ESTUDIOS GALLEGOS", Tomo XLIII, Fascículo 108, Santiago 1996. 
Pitiographia dirixida al obispo don Rodrigo Piñeiro con [8] la descripçión de la granja de Sancta Crux en verso heroico, en la cual se conosçe el ingenio del autor; y [9] el Tumulo Triunphal del invictíssimo Carlo Quinto Cesar Augusto Enperador de Romanos, dirixido al clarísimo rey Philipe nuestro señor». De la manera consabida, la enumeración concluye con la mención genérica de «otras obras que están impresas» ${ }^{63}$

Dejando de lado el tópico final, normal en relaciones de esta clase, y completadas debidamente las entradas, parece que podemos identificar los títulos con los impresos que poseemos ${ }^{64}$. Nos limitamos en el elenco siguiente a las obras de mayor fuste desde el punto de vista tipográfico, añadiendo en las notas pertinentes las piezas menores que, como ocurre a menudo en esta época, acompañan cualquier edición. Creo que, todo sumado, representa la totalidad de las obras de Cadaval dadas de alguna manera a la imprenta:

[1] In librum quartum Antonii Nebrissensis de Constructione decem partium orationis Cadabalis Grauii Calydonii lucidissima explanatio,

\footnotetext{
${ }^{63}$ Desde ciertos puntos de vista hay que poner en relación la lista de obras de esta pregunta con la que se enuncia sin ánimo de ser completa en la primera de las súplicas al Rey: «este Tumulo Triumphal que compuse y escrivi en honor y çelebridad del invictisimo emperador Carlos V Cesar... y los tumulos que ansimismo escrivi y compuse en recomendaçion de las serenisimas prinçesa de Portugal dona Maria y reyna dona Ysabel». Parecen un tópico de ocasión las siguientes frases de la segunda súplica: «estoy escriviendo en prosa y verso latino las memorables hazañas... del invictissimo emperador Carlos..., su muy caro y amado padre de Vuestra Magestad, y ansimismo de Vuestra Magestad y del renesisimo prinçipe Don Juan de Austria, su caro y amado hermano de Vuestra Magestad». Se observa que Cadaval receuerda en cada momento lo que más le interesa en las respectivas situaciones.

${ }^{64}$ Señalo, porque esto es siempre muy importante para analizar la difusión de las obras compuestas por humanistas, que casi todas las obras mencionadas a continuación se encuentran: en la Biblioteca Universitaria de Santiago, en la Biblioteca Nacional de Madrid, en la Biblioteca Nacional de Lisboa, en la Biblioteca da Ajuda en Lisboa, en la Biblioteca Pública de Évora (antes de la Universidad), en la Biblioteca Nacional de Rio de Janeiro, y en la Biblioteca Pública de Braga. No todo está en todas partes, pero sí las obras más significativas, lo que supone una circulación bastante aceptable. Sin ánimo de ser exhaustivo, y sólo para ilustración, señalaré en cada edición las Bibliotecas en que se encuentra y su signatura, si he logrado averiguarla (doy nombre de la ciudad, referencia $\mathrm{BN}$ (acional), BU(niversitaria) o BP(ública) y la cota).
}

"CUADERNOS DE ESTUDIOS GALLEGOS", Tomo XLIII, Fascículo 108, Santiago 1996. 
Lisboa, Ex officina Francisci Correa, $1565^{65}$. Haec breviter Cadabal quondam dictavit in urbe Amphilochi nota quae dicitur Aurens Ensis, 54 hojas $^{66}, 4^{\circ} .{ }^{67}$

Breve parlamento que hizo el orador y poeta Alvaro de Cadabal Valladares de Sotomayor al mui alto y poderoso señor don Sebastián, Rei de Portugal... quando le offresció la Paraphrasis que compuso sobre el Quarto libro de Antonio de Nebrissa, çerca de la construçion de las partes de la Oraçion, con una salutación a nuestra Señora, Lisboa, Francisco Correa, 1565, 3 hojas, $4^{\text {o68 }}$

[2]+[3] De Obitu et Apotheosi invictissimi Ioannis tertii Lusitaniae...regis, ... qui anno 1557 tertio Idus Iunii ad superos concessit. Necnon de miseranda serenissimae Reginae Catharinae lamentatione opus a Cadabale Grauio Calydonio cum scholiis et annotationibus in lucem editum ${ }^{69}$, Lisboa, Excudebat Franciscus Correa, 1565,22 hojas, $4^{\circ} .^{70}$

${ }^{65}$ El texto va precedido de un poema dedicatorio al rey Don Sebastián (Ad praecellentissimum invictissimumque Sebastiarnum... regem... Cadabalis Grauii Calydonii carmen).

${ }^{66} \mathrm{Al}$ final van tres poemas, de los cuales uno de Diogo de Arroio, otro de Cadaval, y un tercero anónimo. Sigue una carta de Cadaval a Jeónimo Campano, y en f. $54 \mathrm{v}$ un poema latino de Simón Roscio, el discípulo de Cadaval en Orense (véase además la nota a la Apotheosis)..

${ }^{67}$ Ej.: Santiago BU 18303.- Lisboa BAjuda.- Évora BP.

${ }^{68}$ Ej. Madrid BN

${ }^{69}$ La misma obra había sido ya impresa por Juan Blasio de Colonia, en Lisboa 1563 (De obitu et apotheosi invictissimi Ioannis tertii Lusitaniae et Algarbiorum regis...necnon de miseranda ... Reginae Catharinae lamentatione opus a Cadavale Gravio in lucem editum). Ej. de esta edición en Évora BP.

${ }^{70}$ Contiene varias piezas accesorias de interés para la vida de nuestro autor: f. $5 \mathrm{v}$ Ad... Reginam Catharinam cuiusdam Ulyssiponensis poetae supplicatio ne ad proprios lares Cadabalem Gravium Calydonium remeare patiatur; f. 6 In obitum et apotheosim ... Ioannis tertii Cadabalis Gravii Calydonii funebre carmen; f. 13v In obitum... Ioannis tertii... Reginae Catharinae lamentatio a Cadabale Gravio Calydonio edita; f. 17v Serenissimae... principis Mariae... epitaphium a Cadabale Gravio Calydonio editum...; f. $19 \mathrm{v}$ De miseria humanae conditionis ad prudentissimam reginam Catharinam brevissima relatio...; f. 22v In quosdam rusticos poetastros et Cadabalis Gravii Calydonii praeceptoris sui honorem, studiosi adolescentis Simonis Roscii, Paschalis Roscii ciuis Auriensis filii, non vulgare carmen.

Ej. de esta segunda edición: Santiago BU 18303.- Madrid BN R 11358(1).-Lisboa BN Res 2240(2)P.-Rio de Janeiro BN 28.3.4(2).- Évora BP.- Braga BP.-Lisboa BAjuda

"CUADERNOS DE ESTUDIOS GALLEGOS", Tomo XLIII, Fascículo 108, Santiago 1996. 
[4] De magno atque universali cataclysmo ichthyotyrannideque liber in Lusitanorum regum gratiam et commendaionem a Cadabale Grauio Calydonio in lucem aeditus ${ }^{71}$, Lisboa, Excudebat Franciscus Correa, 1565, 24 hojas, $4^{\circ} .{ }^{72}$

Rithma en honor, celebridad y recomendación del illustrissimo ... señor el Obispo don Julian de Alba, capellan mayor del ... Rey don Sebastian... Con relación de la hedad de oro, en la qual Saturno reynó, $y$ de la hedad de hierro en que agora vivimos, Cadaval Gravio Calydonio author, (Lisboa, Francisco Correa, 1566), 6 hojas $^{73}, 4^{\circ}$. Lo sigue inmediatamente, como obra suelta:

In praeclarissimi atque beneficentissimi episcopi Iuliani de Alba rerum sacrarum Regii Praefecti corporis et animi egregias dotes elegans ac brevis Apographia, Cadabale Grauio Calydonio authore, (Lisboa, Francisco Correa, 1566), 14 hojas ${ }^{74}, 4^{0} .{ }^{75}$

[5] Brachylogia. Invictissimorum ac perinde clarissimorum triumphaliumque Lusitaniae Regum Herculisque monstrorum domitoris laborum ad prudentissimum... Principem Eduardum... cum eiusdem luculenta commendatione brevissima relatio, quae Brachylogia sive Laconismus inscribitur. Ac simul de praestantissime Principis Mariae,

\footnotetext{
${ }^{71}$ Hay una primera versión que coincide totalmente en el texto del poema, pero que carece de otras adherencias, bajo el título De Ichthyotyrannide liber in Lusitanorum regum gratiam et commendationem a Cadabale Grauio editus, Lisboa, Ex officina Ioannis Blasii de Agrippina Colonia, 1563, 8 hojas, $4^{\circ}$. Ej. de esta edición Lisboa BN 217(1)V

${ }^{72}$ Después de los capítulos pertinentes del Génesis que funcionan como argumento, aparece la dedicatoria del poema al Cadenal-Infante Don Henrique. Después del poema de Cadaval sige un poema de un Cuquegio Auriensigena; de este orensano no se sabe nada como escritor y latinista. En f. $22 \mathrm{v}-24$ se encuentran diversas composiciones menores de Cadaval, en prosa, para acabar con dos pequeños epigramas latinos.

Ej.: Santiago BU 18303.- Madrid BN R 11358(2).- Lisboa BN Res 2966V.-Lisboa BAjuda.- Évora BP.-Braga BP

${ }^{73}$ Se trata en realidad de un poema, al que sigue un soneto, dedicado al mismo, que aparece en f. 5; en f. 6 unas composiciones latinas

${ }^{74}$ Interesa señalar en primer lugar que la dedicatoria a Don Julián de Alba va datada en Lisboa a 11 de enero de 1566. Tras ella aparecen dos poemitas sáficos en honor del personaje, así como varias piezas dedicadas al Don Julián por dos portugueses. Cierran el impreso en f. 14 dos nuevos poemas de Cadaval al ilustre capellán real.

${ }^{75}$ Ej.: Santiago BU 18303.- Madrid BN R 11358(3).-Lisboa BN Res 217(3)V.- Rio de Janeiro BN W.1.5.30 (1)
}

"CUADERNOS DE ESTUDIOS GALLEGOS", Tomo XLIII, Fascículo 108, Santiago 1996. 
illustrissimique viri Alexandri Farnesii, Parmae necnon Placentiae Principis nuptiis Bruxellae celebratis tertio Idus Novembris anno 1565 Cadabale Gravio Calydonio autore, Lisboa, Excudebat Antonius Gonsales, 1568, 32 hojas $^{76}, 4^{0} .{ }^{77}$

[6] Ad Magnificentissimum illustrissimumque Principem Antonium... Lusitaniae Regis Emmanuelis non aspernandum nepotem Cractique Priorem, Cadabalis Grauii Calydonii Monocolon Encomiasticonque carmen, Lisboa, Excudebat Antonius Gonsales, 1568,8 hojas, $4^{\text {o }} .^{78}$ Sigue como obra propia:

[7]+[8] Pityographia. In amplissimas Illustrissimi Praestantissimique Doctoris Roderici Pinarii Portugallensis Episcopi laudes egregiasque dotes cum generis, titulorum ac virtutum eiusdem insigni commendatione graphicaque ornatissimae villae Sanctae Crucis de Maia descriptione libri duo cum annotationibus et scholiis, Cadabale Grauio Calydonio authore, Lisboa, Excudebat Antonius Gonsales, 1568,28 hojas $^{79}, 4^{\mathrm{o}} .80$

[9] Invictissimi Caroli Quinti Caesaris Augusti Romanorum Imperatoris, Hispaniarum Clarissimi Regis, Triumphalis condignusque Tumulus, Cadabale Gravio Calydonio Tydensi authore, Lisboa, Excudebat Antonius Gonsales, 1568, 26 hojas $^{81}, 4^{\circ} .{ }^{82}$

Merece especial mención un pliego impreso por el primer editor que se ocupa de las obras de Cadaval, a saber Juan Blasio, tipógrafo natural de Colonia, que imprimió en Lisboa entre 1554 y 1563 más de medio

${ }^{76}$ En el f. 2 se encuentra un poema encomiando la obra de Cadaval, debido a un «doctissimi cuiusdam sacrae Theologiae Doctoris», que ignoro quién sea (¿acaso el propio Cadaval?).

${ }^{77}$ Ej.: Madrid BN 17323(2).-Lisboa BN Res 3429V.-Rio de Janeiro BN 23.2.5 (4).

${ }^{78}$ Ej.: Madrid BN R.17323(3).-Rio de Janeiro BN23.2.5(5)

${ }^{79}$ Presenta al comienzo una carta laudatoria de Joâo Rodrigues de Sá al autor, fechada en Porto a 29 de agosto de 1568, y de éste mismo una alabanza latina del Obispo Pinheiro. Hay también una carta del obispo a Cadaval. Cierra el impreso un poema de un Andreas Marsupinus de Florencia.

${ }^{80}$ Ej.: Madrid BN R 17323(4).-Lisboa BN Res 217(4).-Évora BP Res 64(4)

${ }^{81}$ En f. 2 una larga dedicatoria al rey Felipe II. En f. 20v Serenissimae ... principis Mariae... inuictissimi Philippi Hispaniarum Regis clarissimae uxoris... Epitaphium. Suguen hasta el fin diversas pequeñas composiciones del propio Cadaval.

${ }^{82}$ Ej.: Madrid BN R 17323(1)

"CUADERNOS DE ESTUDIOS GALLEGOS", Tomo XLIII, Fascículo 108, Santiago 1996. 
centenar de obras. El pliego parece pertenecer a algunas de las obras publicadas en su casa por Cadaval. Por su interés innegable trascribo las noticias que da Anselmo ${ }^{83}$ sobre el ejemplar, aparentemente único, que estaba en su tiempo en Coimbra: se trata de unas hojas con tres composiciones métricas : a) In laudem Balthasaris Limpis... Archiepiscopi Bracharensis; b) Ad dominum Gasparem de Avellaneda de Stuniga Compostellanensem Archiepiscopum; c) De laboribus Herculis, que no llevan título ni paginación, pero al final sí el colofón del tipógrafo y la data de 1563.

Un punto interesante lo marcan dos hechos: en primer lugar, la limitada, pero nada despreciable, difusión de estas publicaciones, que circularon de preferencia en territorio portugués, a pesar de que el propio autor asegure con gran énfasis y optimismo que se habían difundido por todas partes con notable éxito de crítica; y en segundo lugar, la noticia que nos transmite el Inventario de los bienes dejados por Cadaval a su muerte. En él se menciona, además de los libros que quedaban entre sus propiedades, «otra ucha con papeles en que se recontó lo siguiente: está llena de obras suyas del dicho cadaval desencadernadas». Habida cuenta de la reducida tirada que solía hacerse de las obras impresas, sobre todo cuando no se trataba de obras de gran comercio, parece oportuno y justo sospechar que, además de los ejemplares dedicados por él mismo a personajes portugueses de nota, una buena parte de su producción yacía encerrada en este arcón conservado entre sus bienes.

Una vez registradas las obras impresas, merece la pena que prestemos atención a un notable proyecto, largamente madurado por nuestro personaje, del que solamente llegamos a saber algo por una de las fases a que lo sometió el autor. Concibió, en efecto, un gran estudio que responde con criterios humanistas, bien entendido, al título que le dio: Descripción y Geografía de Galicia. Sabemos de él por una serie de documentos de 1569 , que nos proporcionan bastante material, por desgracia insuficiente, para hacernos cargo cabal de los intentos de Cadaval. Imaginó nuestro latinista que había llegado la hora de abordar un estudio que en buena

${ }^{83}$ A. Joaquin Anselmo, Bibliografia das obras impressas en Portugal no século XVI, Lisboa 1906, al que debo varios detalles tipográficos y de contenido sobre las publicaciones de nuestro autor. He buscado, sin resultados, estos impresos en la Biblioteca da Universidade de Coimbra. 
parte, brillante pero insuficientemente, acababa de hacer también el canónigo de Mondoñedo, Licenciado Bartolomé Segura de Molina ${ }^{84}$. Cadaval había llegado de Portugal poco antes, donde no logró todos los patrocinios que deseaba y necesitaba, y acababa de ganar de nuevo por oposición la Cátedra de Medianos de Santiago.

El Maestro Cadaval cae en la cuenta de que para un propósito de tal envergadura necesitaba un apoyo muy fuerte, y supuso, basándose en otros precedentes, que éste sólo le podía venir del propio rey de España, Felipe II. En consecuencia se apresta a dirigirse al rey. Para solicitar el patrocinio regio, ya que no cuenta en la corte de Madrid con los conocimientos de que había dispuesto en Lisboa, y que le habían servido al menos para lograr la publicación de todas sus obras, se hace a la idea de que la demanda debe ir acompañada de una documentación, que diríamos de idoneidad y capacidad. Para ello, en agosto de 1569 inicia ante el justicia mayor y alcalde de Santiago dos informaciones en que distintos testigos depondrán respecto a una serie de preguntas formuladas y organizadas por el propio Cadaval: el primer interrogatorio se refiere a su condición personal, capacidad e historial literario; el segundo se orienta a ponderar el interés, viabilidad y complejidad del proyecto ${ }^{85}$.

${ }^{84}$ Descripción del Reyno de Galizia, Mondoñedo, Agustín de Paz, 1550; edición facsímil de J. Filgueira Valverde, Pontevedra (Bibliófilos Gallegos, I) 1949.

${ }^{85}$ El original de los interrogatorios se conserva en Santiago, Archivo Catedral, Varia, pero en tan mal estado que el primero está prácticamente inutilizable, el segundo se conserva bien. Fue publicado por López Ferreiro en 1908 (véase a este respecto mi nota 42), y aprovechado varias veces, hace poco por Ogando, art. cit. nota 9. He tenido la suerte de conocer todo el expediente gracias a la inestimable ayuda de mi amigo y colega el P. José García Oro OFM. El expediente se encuentra en Simancas, Archivo General del Reino, CC 425, y consta de la copia notarial íntegra de las dos informaciones abiertas en Santiago a ruegos del propio Cadaval en 16 de agosto de 1569 y cuyos traslados fueron firmados por el escribano de número Alonso Rodriguez Ramiro el 6 de octubre del mismo año, más dos súplicas al rey, de las que una se refiere a nuestro asunto, mientras que la segunda, podría decirse que aprovechando la ocasión y la circunstancia de encontrarse Cadaval en Madrid, es una petición para que el rey acceda a otorgarle la jubilación a la vista de los años pasados en la docencia universitaria. Las informaciones (como ya era sabido en parte) consisten en dos series de preguntas formuladas por el propio Cadaval y las series de respuestas de los testigos presentados por él mismo para que testifiquen en verdad. La primera información versa sobre siete preguntas y se hace a ocho testigos; la segunda de cinco preguntas es respondida también por ocho testigos, los mismos de la información anterior. Las súplicas al rey Felipe II, aparecen hechas

"CUADERNOS DE ESTUDIOS GALLEGOS", Tomo XLIII, Fascículo 108, Santiago 1996. 
Debidamente autenticado todo el interrogatorio y respuestas, Cadaval lo acompañará como pieza argumentativa a su petición al rey, dándole así una forma que creía más objetiva al consabido memorial en que se formulaban todas las peticiones a la Corona.

La obra se encuadra en un movimiento general en que se publican muchos estudios de carácter geográfico, con participación de notables humanistas y eruditos. En España habría que mencionar el apasionante proyecto de Juan Páez de Castro, asumido por Felipe II poco después de la muerte del cronista real ${ }^{86}$, en el que no sería extraño que se llegase a descubrir que acaso se explotó de alguna manera el proyecto de Cadaval. Éste calculaba primero «dos años y más» para su ejecución, pues habría de recorrer y observar todo el reino ${ }^{87}$; pero poco después el plazo se extendía al estimar Cadaval que la obra sólo «se puede acabar en quatro años» ${ }^{88}$. La complejidad del plan de Cadaval consiste en que, además de los materiales literarios y documentales que apoyarían la descripción del reino de Galicia, iría todo acompañado de imágenes de toda clase, representando monumentos, paisajes y piezas singulares. Todo este aparato

desde Madrid, adonde se había trasladado para actuar mejor en la corte: «atento que vengo a mi costa y soy hijodalgo pobre y no podre sustentarme en esta corte muchos dias», escribe Cadaval en la primera; «he venido a esta corte de Vuestra Magestad a mi costa aunque de parte del reyno de Galizia», dice en la segunda. Ninguna de estas súplicas al Rey lleva fecha, pero hay que suponer que deben ser del invierno del mismo año de 1569 , o primavera de 1570 . Todo el conjunto será publicado próximamente por García Oro en Compostellanum, por lo que no quiero entrar aquí en mayores detalles. He usado en numerosas notas a lo largo de este trabajo todo este material, del que he llegado a ofrecer párrafos enteros; de ellos se deduce claramente cuánto merecerá la pena leerlo íntegramente cuando aparezca impreso.

${ }^{86}$ Véase Ogando, art. cit. nota 5, 122-123, basñandose en parte en J. Gavira, «Las Relaciones histórico-geográficas de Felipe II», Estudios Geográficos, 11 (1953)

${ }^{87}$ En la segunda información, pregunta 4.

${ }^{88}$ Así en la mentada súplica a Felipe II. En ella solicita para él y para sus colaboradores la suma de mil ducados por año. Es curioso que en esta petición se entra en ciertos detalles sobre el destino de tan notable cantidad: "porque han de intervenir en tal obra iluminadores, abridores de tablas, escrivientes $t$ aguazil con provision real que haga abrir los archivos y dar posadas, porque tengo de andar todo el Reyno en persona y ver todo al ojo y tomar relación de todas las antiguallas y descubrir piedras, sepulchros, coronas y epitaphios que estan medio enterrados». Se ofrece al Monarca una alternativa, porque «si fuera servido que la tal Geographia se escriva sin estampas bastan mil ducados y se puede acabar en dos años».

"CUADERNOS DE ESTUDIOS GALLEGOS", Tomo XLIII, Fascículo 108, Santiago 1996. 
gráfico buscaba sólo imitar el método seguido en las numerosas ediciones de Ptolomeo aparecidas en la primera mitad del siglo XVI ${ }^{89}$, que tuvo presente nuestro latinista ${ }^{90}$ como modelo al diseñar su obra.

Su objetivo era describir por entero Galicia, desde el punto de vista geográfico, histórico y documental, ilustrando cada población o comarca con los documentos de toda clase que fueran pertinentes, tanto archivísticos como arqueológicos, así como con las noticias y explicaciones sacadas de los autores antiguos. Se proponía, sin embargo, llevar a cabo este estudio sobre el terrreno, realizando incluso prospecciones en los yacimientos que las merecieran. Parece que intentaba apartarse de tratamientos anteriores, acaso como el de Molina, para evitar acumular leyendas y consejas, que estimaba ajenas al verdadero saber. Pero quería realizar obra que llegara al gran público, para lo cual había decidido escribir los textos en latín y romance, ignoramos de qué manera y en qué proporción. La obra nunca pasó de la fase de proyecto, porque el rey Felipe no tomó ninguna provisión al efecto, y porque Cadaval debió entrar pronto en estado deficiente de salud.

Por otro lado, importa tener presente cómo su obra toda y el personaje cayeron prácticamente en el olvido. Ciertos recuerdos locales, entre los cuales figuraba a no dudar la inscripción tantas veces recordada del Colegio de Fonseca, permitieron que se le mencionara alguna que otra vez ${ }^{91} \mathrm{y}$ un poco de pasada, sin que figure en ninguno de los grandes repertorios literarios, a que tendría derecho por la indudable calidad de sus escritos. Ha sido en Portugal, donde no logró alcanzar los recursos y los padrinazgos que buscó en los postreros años de su vida, donde las publicaciones le

\footnotetext{
${ }^{89}$ Anoto que sólo en la Biblioteca Universitaria de Santiago existen actualmente ejemplares de las ediciones de Ptolomeo aparecidas en Estrasburgo en 1520 y 1525 , Lyon 1535 y 1541, y Venecia 1547.

${ }^{90}$ En efecto, lo dice él específicamente: «y an de ser las estanpas por la horden de Ptolomeo y la historia devaxo, y de esta manera sera obra muy ynsigne y de mucho lustre y muy preçiada de todas las personas de buen entendimiento» $\left(\left(2^{\circ}\right.\right.$ pregunta del $2^{\circ}$ interrogatorio).

${ }^{91}$ Pienso que fue la dicha inscripción, y algún recuerdo no siempre muy preciso, lo que lo convirtió en uno de los fundadores de la Universidad de Santiago, cuando se diseñaron y ejecutaron las estatuas y medallones que adornan el centro del cuerpo superior del antiguo edificio de la Universidad, ampliación promovida por Montero Ríos.
}

"CUADERNOS DE ESTUDIOS GALLEGOS", Tomo XLIII, Fascículo 108, Santiago 1996. 
dieron cierto brillo. Escaso lustre, en todo caso, para un personaje que en su vida y en su corta producción mostró un amor al mundo antiguo y a su tierra ${ }^{92}$ como se encuentra pocas veces. Bien pudiéramos decir que de no haber mantenido vivo su recuerdo la inscripción compostelana arriba referida, quizás su memoria habría quedado limitada a alguna mención escondida de algún bibliógrafo avisado ${ }^{93}$.

El brillante humanista tudense, que cabe denominar también (pace ipsius) compostelano por su presencia y actividad provechosa en la Universidad de Santiago, dio muestra e indicio de su vasto saber, no sólo clásico sino de su tiempo ${ }^{94}$ en su obra y en sus malogrados proyectos.

Sean estas páginas homenaje sincero y devoto al ilustre primer latinista de la Universidad compostelana, que abrió horizontes singulares en su azarosa y refulgente historia. Quiero así honrar en la medida de mis fuerzas, pero muy cordialmente, a uno de mis eruditos y activos predecesores.

${ }_{92}$ Véase el trabajo de Ogando Vázquez, citado en la nota 9.

${ }^{93}$ Un erudito tan meticuloso como fue Diogo Barbosa Machado lo menciona de pasada como ilustre amigo de Don Rodrigo Pinheiro (véase arriba la obra [7]) en su Bibiotheca Lusitana Histórica, Critica e Cronologica, III, Lisboa 1750. En cambio no lo menciona Nicolás Antonio.

${ }^{94}$ Ramalho, cit. nota 2, recuerda que en el poemita dedicado al arzobispo compostelano Zúñiga (véase arriba obra [11]), da en forma métrica algunas frases tomadas del tratado De platano de Sá de Meneses, que relaciona con el avellano, lo que le permite jugar con el apellido del arzobispo Zúñiga de Avellaneda.

"CUADERNOS DE ESTUDIOS GALLEGOS", Tomo XLIII, Fascículo 108, Santiago 1996. 


\author{
APÉNDICE ${ }^{95}$ \\ I. El testamento de Cadaval \\ Santiago, Arch. Catedr.Varia $1^{\text {a }}$ serie, Tomo III, f. 398
}

Testamento del maeso Cadabal.

In Dei nomine, amen. Sepan quantos esta carta de manda y testamento vieren como yo el maeso Albaro de Cadabal vezino de la çiudad de Santiago que soi presente estando enfermo de la enfermedad que Nuestro Señor me dio y con my seso e juizio natural ago y hordeno mi testamento por el qual encomiendo mi anima a my senor Jesus Christo que la conpro e redemio por su preçiosa sangre en la arbol de la Santa Cruz, e ruego e pido por merçed a la Vienabenturada Virgen Santa Maria su bendita madre ${ }^{96}$ quiera ser mi ynterçesora y abogada y ruego a su hijo bendito me perdone mis culpas e pecados para que aunque yndino y pecador meresca entrar en su Santa Gloria, amen.

Iten mando que mi cuerpo sea sepultado en la çiudad de Tuy y en la iglesia de Nuestra Senora de la dicha çiudad de Tuy en la sepultura donde paresçiere a mi conplidor.

Iten mando al clerigo questobiese comigo al tienpo de mi fallesçimiento y encomendare mi anima a mi Señor Jesus Christo dos reales.

Iten mando que se sigan por mi anima treynta misas las nuebe cantadas y las mas rezadas en las iglesias e monesterios que paresçieran a mis conplidores.

Iten dexo por conplidor y executor deste mi testamento e lo en el contenido a Diego Xuarez de Tangill canonigo en la Santa Iglesia de Santiago mi Senor e doi poder conplido para que cunpla este mi testamento y lo mas que viere conviene para escargo de mi conçiençia.

Iten dexo y nonbro por mi heredero de todos mis vienes de cualquiera calidad que sean e por qualquiera causa, herençia e subçesion que me perthenezcan al dicho señor canonigo Diego [fol. 398v] Xuarez de Tangill para que los aya e llebe y dellos y en ellos aga e disponga lo que viere conbiene y le paresçiere.

Iten mando a la Santa Cruzada redençion de cavtibos diez maravedis y con esto le aparto de mys vienes.

E reboco anulo e doi por ninguno e de ningun valor efecto otros qualesquiera testamentos que antes de agora aya fecho e otorgado para que no valan ni agan fee sino este que al de presente otorgo ante bos Gonçalo de Regeira escrivano del numero e cavildo de la Santa Iglesia e çiudad de Santiago que quiero vala como my testamento, ultima y postrimera boluntad y lo otorgo de la manera susodicha. Que fue fecho e otorgado en el barreo de Mazarelas, estramuros de la dicha çiudad, a siete dias del mes de março de mill e quinientos y setenta y çinco anos.

Estando presentes por testigos Antonio de Ballesteros y Jacome Fernandez, pelexero, y Françisco de Lage, herrero, e Juan da Hermida, vezinos de la feligresia de Santiago de Tabeyros e Juan Peres, criado de mi serviçio e yo escrivano doi fee conozco al dicho otorgante ques el mismo, e por estar congoxoso con la enfermedad y no poder firmar lo firman a su ruego el dicho Juan Perez, Antonio de Ballesteros e Jacome Fernandez de sus nonbres.

\footnotetext{
${ }^{95}$ Sobre estas transcripciones véase arriba n. 42.

${ }^{96}$ Tachado: me perdone mis
}

"CUADERNOS DE ESTUdIOS GALLEGOS", Tomo XLIII, Fascículo 108, Santiago 1996. 
el $\mathrm{m}^{\circ}$ al $\mathrm{Ab}$ de $[$ sic $]$ -

Juan Perez (rubricado).- Antonio de Ballesteros (rubricado).- Jacome Fernandez (rubricado).- Paso ante mi Gonçalo Regeira, notario.

\section{Inventario de los bienes de Cadaval}

Santiago Arch. Cat. Varia $1^{\text {a }}$ parte, Tomo III f. 399

Requento de los bienes de Cadabal.

En la çiudad de Santiago a diez dias del mes $<\ldots . . .>^{97}$ el mui magnifico e mui reverendo senor Diego Suarez de Tangill, canonigo en la Santa Iglesia de Santiago, dixo quel maeso Alvaro de Cadaval abia echo testamento y le abia dexado por su conplidor y heredero y abiase falesçido desta presente vida y açetando como dixo açetaba su herençia con benefiçio de ynbentario, costas que valieran y montan e no mas ni alliende, e para conplimiento de su anima e descarga de anima e conçiençia entro en el aposiento donde se falesçio el dicho Alvaro de Cadabal questaba cerrado y fechado, e por ante mi escrivano e los testigos infraescritos reconto e hizo recuento de bienes que alla tenia y del ficaron al tienpo de su falesçimiento, pieça por pieça en la forma e manera seguiente:

Primeramente:

Iten una arca vieja a la qual se abrio con su llabe e dentro della se allo lo seguiente:

Iten una manta dalbeo vieja.

Iten otra manta dalbeo usada.

Iten otra manta dalbeo usada.

Iten dos almoadas blancas llanas.

Iten otras dos almoadas viejas, la una con un labor de seda colorada y la otra con lavor de seda negra vieja.

Iten un cobertor de lana colorado viejo.

Iten una sabana delgada de lienço vieja.

Iten otra sabana destropeada usada.

Iten unos manteles dalamanisco usados.

Iten una camisa de lienço medeada.

Iten mas una faseleja blanca vieja desfilada de red

[f. 399v]Iten un abito de flaire blanco usado.

Iten un pedaço de pano $<\ldots . .>$ nuebo.

Iten mas un al herraruelo de pano negro medeado.

Iten una ropa de raja aforrada en baeta y el colen aforrado en raso.

Iten un manteo de pano negro usado con un rebeton de raso por dentro.

Unas calças llanas negras.

Unos talabartes sin petrina.

Unos saquelo viejo de muger de pano negro.

Iten una serbilleta de mesa.

Iten un pano viexo de manos de lienço.

Unos gorgillos biejos de un niño.

Unos canos biejos de unas botas.

Dos pedaçillos de nascole biejos.

${ }^{97}$ Debe suponerse que se trata del mes de abril de 1575 , ya que el día 10 de marzo fue la data de fallecimiento de Cadaval.

"CUADERNOS DE ESTUDIOS GALLEGOS", Tomo XLIII, Fascículo 108, Santiago 1996. 
Un pedaço de una red de pescar.

Iten una espada.

Iten en el estuche de la dicha arca se allo catorze cucharas de palo y una escobilla vieja.

Iten una maleta vieja.

Iten unos çapatos topetados.

Los quales dichos bienes fueron lo que se allaron en la dicha arca de que yo escrivano doy fee e se bolvieron alla y se fecho con llave.

Iten allo otra arca biexa en la qual se recontro lo seguiente:

Un enbultorio de papeles ynpremidos por $<\ldots . .>$

[f. 400]Iten un cesto.

Iten un ferrollo con su fechadura sin llave.

Iten un pichel estrano.

Iten una escodella de palo e un plato de barro.

Dos sonbreros de tafetan biejos.

Un mortero de palo.

Unos çapatos de nino.

Unos cuerpos de sayo sin mangas.

Una cuchara de hierro.

Una tijola de cobre.

Una cuchara de ferro.

Un saco biejo, otro saco viejo que son dos.

Una almoada labra bieja.

Iten un barrill con pieças de hierros biejos.

Lo qual se bolbio a la dicha arca y en ella no se allo otra nenguna cosa.

Iten mas una capa de pano negro usada larga.

Mas una camisa destopa chica.

Tres tablillas biejas de un caxon.

Iten un balesta de bodoque.

Iten otra balesta de azero chica.

Iten un arcabuz con su caja de cuero digo que es pestolete.

Iten un frasco con frasquillo de cuerno

Iten tres dagas, las dos con bainas de terçiopelo e la una de cuero.

Iten otras dos espadas.

Iten una bota bieja e una calabaça.

Iten una caja para una jarra que es bieja.

[f. $400 v]$ Iten otra red con sus chunbos.

Iten dos mantas dalbeo biejas.

Un $<$... >ton biejo.

Un paño viejo con $<\ldots .>$

Otra arca de libros en la que se allo los libros seguientes:

Ferrala sobre los salmos en un tomo.

Ponponio Mela en un tomo.

Obidio Amatoria en un tomo.

Luciame en un tomo.

Plinyo en un tomo.

"CUADERNOS DE ESTUDIOS GALLEGOS", Tomo XLIII, Fascículo 108, Santiago 1996. 
Silio Italico en un tomo.

Platon en un tomo.

Tito Libio quarta decada en un tomo.

Retoreca de Tulio en un tomo.

Oraçio en un tomo comentado.

Prisçiano en un tomo.

Lesicon en un tomo.

Epistolas de Siceron en un tomo.

Suetonio en un tomo.

Biblia en un tomo.

Jubenal en un tomo.

Filipicas de Siçeron en un tomo.

Fera del mundo en romançe

[f. 401] Cosmografia de Pedro Piano en latin en un tomo.

Budeo en un tomo.

Omero en latin en un tomo.

Juaquimo Fortio en un tomo.

Ausonio en un tomo.

Gelio en un tomo.

Lucano en un tomo.

Un brebiario romano de tres liçiones, dizen que es de un estudiante y se llama Gregorio Gonçalez.

Dispanterio en un tomo.

Quinto Curçio en un tomo.

Confesionario en latin en un tomo.

Columela en un tomo.

Marino sobre Plinio en un tomo.

Una arte brea desencadernada.

Titu Libio en romançe en un tomo.

Omero en griego.

Ciçeron Topicos en un tomo.

Birgilio.

Silba Luçiales en un tomo.

Marçial.

Un Testamento Nuebo en griego e latin.

Un Arte de Antonio comentada.

Otra arte de Antonio comentada.

[f. 401v]Plutarco.

Bujsio.

Calepino.

Plutarco en un tomo.

Plinio en un tomo.

Otra Arte de Antonio comentada.

Herasmo sobre Bautista enaçio en un tomo.

Obra en beso de Diego de Quintana, en un cartapazio de Natura Angelica escrito de mano.

"CUADERNOS DE ESTUDIOS GALLEGOS", Tomo XLIII, Fascículo 108, Santiago 1996. 
Salustio comentado.

Lucano en romançe.

Tusculanas de Ziseron en un tomo.

Çiçeron Sobre los Ofiçios en romançe.

Mantuano Las Partenicas en un tomo.

Un cartapaçeo en griego.

Fenestela.

Asquinis en un tomo.

Adenardo.

Justino.

Catulo.

Herasmo De Pronunçiacione.

Titu Libio en latin en un tomo

Aulo gelio en latín en un tomo

[f. 402] Catalogo de los libros proibidos.

Retorica Aristoteles.

Plautu.

Selecta Epigramata.

Juibi en griego.

Exerçitaçio minoritano.

Omero.

Suetonio.

Ortografio griega.

Un libro en griego.

Otro Arte griego.

Tebio Bracarensi en un tomo.

Cristoforo Longelico en un tomo.

Muerte de la reina dona Ysavel de la Paz en romançe.

Flores Epigramatica.

Argonautico.

Tolomeo en un tomo.

Medezina portatil en un tomo.

Ilenardo.

Los quales dichos libros se quedaron en la dicha arca.

Iten otra ucha con papeles en que se reconto lo seguiente:

[f. 402v] esta llena de obras suyas del dicho Cadaval desencadernadas.

Iten mas un balandran pardo.

Iten un queso de Ingalaterra.

Iten dos arquillas biejas con papeles de borradores.

Quatro pellicas de raposos.

Una silla de palo.

Otra silla de palo.

Otra camisa.

Un tintero e un cochillo.

"CUADERNOS DE ESTUDIOS GALLEGOS", Tomo XLIII, Fascículo 108, Santiago 1996. 
Los quales dichos bienes fueron que se allaron en el aposiento que tenia el dicho Alvaro de Cadaval e segun aqui ban recontados, quedan en el dicho aposiento, de los quales yo escrivano doy fee fueron allados de la manera susodicha. El dicho senor canonigo Diego Xuarez de Tangil fue testigo que si otros bienes algunos obiese y beniesen a su notiçia los declarara e manifestara para que se pongan en el dicho recuento e inventario para que aya cuenta e razon.

[f. 403] Estando a ello presentes por testigos Alvaro Gonçalez e Françisco Porto Dabila e Juan dermyda e Pero Suarez, bezinos y estantes en la dicha çibdad.

Passo ante mi Domingo Cavaleiro, escrivano.

Sin derechos. 